This item was submitted to Loughborough's Research Repository by the author.

Items in Figshare are protected by copyright, with all rights reserved, unless otherwise indicated.

\title{
Transdermal drug delivery by coated microneedles: geometry effects on drug concentration in blood
}

PLEASE CITE THE PUBLISHED VERSION

http://onlinelibrary.wiley.com/journal/10.1002/(ISSN)1932-2143

\section{PUBLISHER}

(c) Curtin University of Technology and John Wiley \& Sons Ltd.

\section{VERSION}

SMUR (Submitted Manuscript Under Review)

\section{LICENCE}

CC BY-NC-ND 4.0

\section{REPOSITORY RECORD}

Al-Qallaf, Barrak, Diganta Bhusan Das, and Adam Davidson. 2010. "Transdermal Drug Delivery by Coated Microneedles: Geometry Effects on Drug Concentration in Blood”. figshare. https://hdl.handle.net/2134/6000. 
This item was submitted to Loughborough's Institutional Repository (https://dspace.lboro.ac.uk/) by the author and is made available under the following Creative Commons Licence conditions.

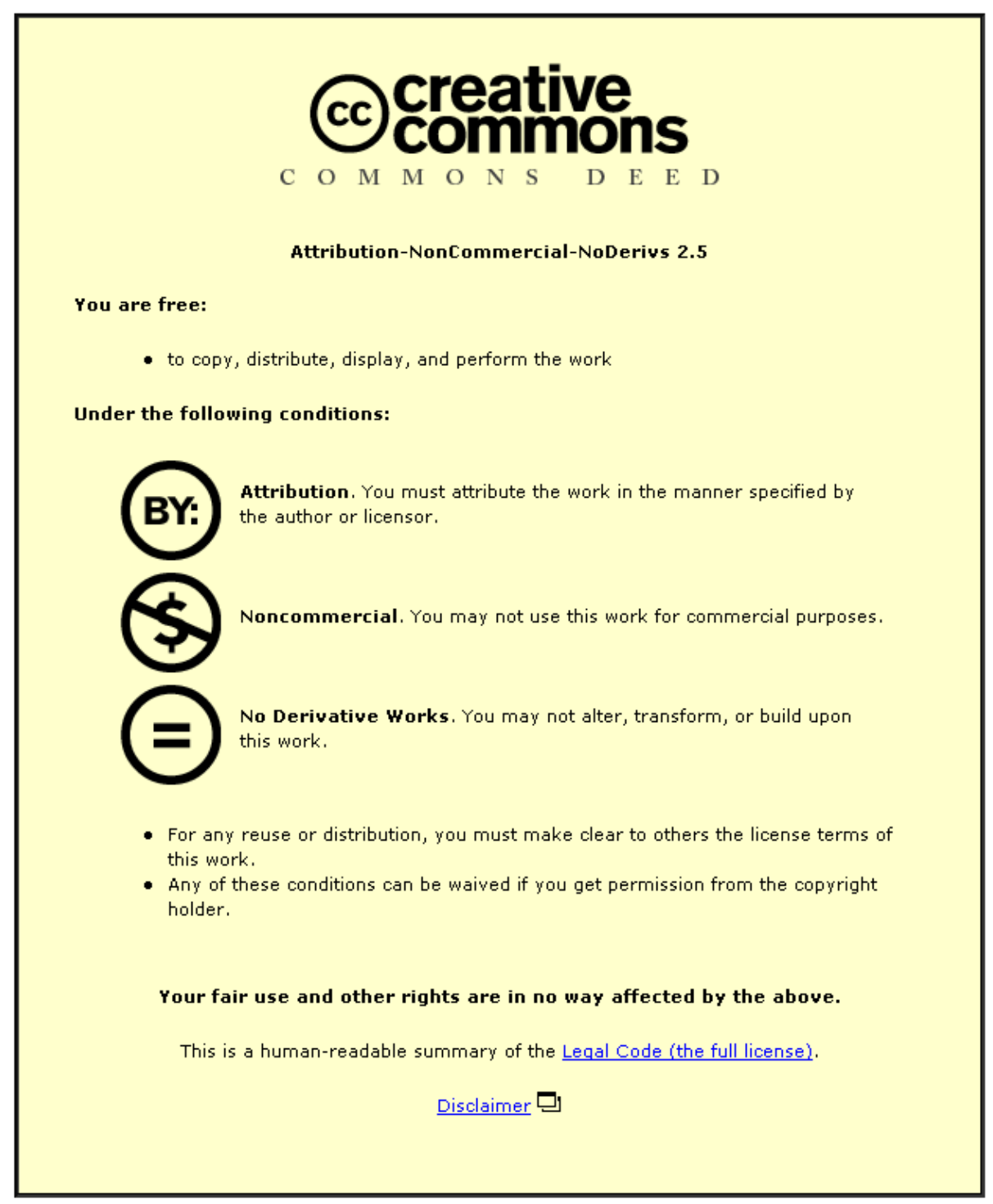

For the full text of this licence, please go to: http://creativecommons.org/licenses/by-nc-nd/2.5/ 


\title{
Transdermal Drug Delivery by Coated Microneedles: Geometry Effects on Drug Concentration in Blood
}

\author{
Barrak Al-Qallaf' ${ }^{1}$, Diganta Bhusan Das ${ }^{2, *}$, Adam Davidson ${ }^{1, \text { \# }}$ \\ 1 Department of Engineering Science, Oxford University, Oxford OX1 3PG, UK
}

2 Department of Chemical Engineering, Loughborough University, Loughborough LE11 3TU, UK

Submitted for Review and Publication in the journal:

Asia-Pacific Journal of Chemical Engineering

23 February 2009

\footnotetext{
*Author for correspondence (Email: D.B.Das@lboro.ac.uk; Tel: 00441509 222509)

\# Current Address: Department of Chemical Engineering, University of Bath, Bath BA2 7AY, UK
} 
Transdermal Drug Delivery by Coated Microneedles: Geometry Effects on Drug Concentration in Blood

\author{
Barrak Al-Qallaf ${ }^{1}$, Diganta Bhusan Das ${ }^{2, *}$, Adam Davidson ${ }^{1, \#}$ \\ 5 \\ 1 Department of Engineering Science, Oxford University, Oxford OX1 3PG, UK \\ 2 Department of Chemical Engineering, Loughborough University, Loughborough LE11 \\ 3TU, UK
}

\begin{abstract}
$\underline{\text { Abshthact }}$
Drug administration through transdermal delivery is restricted by the top layer of skin, the stratum corneum. One possible solution to overcome the barrier function of the stratum corneum is to employ microneedle arrays. However, detailed theoretical models relating drugcoated microneedles and their geometry to the drug concentration in the blood are limited. Thisl paper aims to address this issue by examining the blood concentration profiles for a model drug, insulin, that has been administered via coated microneedles. A mathematical model is introduced and applied to predict theoretical blood concentrations. Furthermore, the insulin concentration in blood is calculated for a range of different microneedle shapes and dimensions to identify the most effective geometry. The results indicate that the optimum microteedle geometry in terms of maximimizing insulin concentration was a rocket shaped needle that has a constant tip angle of $90^{\circ}$. Also, it has been found that the number of microneedles in an array is the most significant factor in determining maximum insulin concentration in the blood $\left(\mathrm{C}_{\mathrm{b}, \max }\right)$.
\end{abstract}

Key ords: Drug concentration in blood, Pharmacokinetics, Transdermal Drug Delivery, Coated microneedles, Mass transfer, Mathematical modelling.

\footnotetext{
"Author for correspondence (Email: D.B.Das@lboro.ac.uk; Tel: 00441509 222509)

\# Cůftent Address: Department of Chemical Engineering, University of Bath, Bath BA2 7AY, UK
} 


\section{Introduction}

In order to understand the mechanisms of microneedle-mediated transdermal drug delivery, it is first necessary to analyze the skin structure. The epidermis consists of two main layers; the stratum corneum (SC) and the viable epidermis (VE). The typical thickness of SC is $10-15$ $\mu \mathrm{m}$ although it can be as much as $40 \mu \mathrm{m}$ in some parts of the human body. ${ }^{[1]}$ The SC consists of fHot layer of dead cells filled with keratin fibres and surrounded by lipids. ${ }^{[2]}$ Below this layer lies the viable epidermis which consists of living keratinocytes and a very small amount of nerve endings. ${ }^{[3]}$ This layer is typically $50-100 \mu \mathrm{m}$ thick. ${ }^{[4]}$ The epidermis is separated from the dermis by a protein rich basement membrane. The dermis forms the majority of the skin volume and contains living cells, a rich microcapillary network and nerve endings. The distathe from the skin surface to the microcirculation has been reported as $200 \mu \mathrm{m} .{ }^{[5]}$ This layer also provides structural support and elasticity to the epidermis layer. ${ }^{[6]}$ The absolute thicknesses of each layer can vary with age, sex and ethnicity, as well as between individuals. Skin thickness also changes according to the anatomical site being considered. ${ }^{[7]}$

It h $\$ 0$ been suggested that in a transdermal diffusion model, the skin acts as a two layer membrane which consists of the SC and the viable skin. When a drug permeates through the viable skin, it is rapidly absorbed by the microcirculation. ${ }^{[5]}$ The stratum corneum is the main barrier to diffusion through the skin. This is due to the diffusion coefficient for drug molecules being typically 500-10,000 times smaller in the stratum corneum than within the viab55skin. ${ }^{[5]}$

Microneedles have been proven to be a useful means to continuously deliver drug molecules to the blood. ${ }^{[8,9]}$ This paper has focused on modelling insulin delivery from a microneedle system. Insulin delivery is needed for various medical reasons such as lowering the blood gluc68e levels in the treatment of diabetes, ${ }^{[10]}$ reducing the infarct size and hence improving the diagnosis of the patient once the stroke occurred, ${ }^{[11]}$ etc. In fact, insulin has been adopted as a model drug in many studies for transdermal drug delivery using microneedles. ${ }^{[10,12-15]} \mathrm{We}$ choose insulin as a model drug for the purposes of this paper.

Arrafged into an array, microneedles are micron-scale projections that penetrate through the stratum corneum, creating pathways through which drugs can diffuse into the deeper levels of the skin. Microneedles are considered to be a hybrid between hypodermic needles and transdermal patches, combining the advantages of both while overcoming their shortcomings. ${ }^{[16]}$ Hypodermic needles are able to effectively deliver a drug but are associated with7pain and the need for medical expertise that generally precludes self-administration. Microneedles can be broadly categorized into two types, hollow or solid (coated). Hollow microneedles have generally received less attention to date as their structure is inherently 
weak and they have practical problems such as the bore hole being clogged by tissue. ${ }^{[17]}$ On the other hand, according to Gill and Prausnitz, ${ }^{[18]}$ coated microneedles could potentially provide an alternative means to systemically deliver drugs in a bolus form. It has been noted that the drug coating should be localised on the microneedle surface rather than the array base. Even though coating the base of the array could increase the dosage, it has been found that the drug is poorly delivered from the array base and instead most drugs are delivered from the tips of the microneedles. ${ }^{[18]}$ For example, when the model antigen 'ovalbumin' was coat 80 onto the tips of a microneedle array its delivery efficiency was increased by $48-58 \%{ }^{[19]}$ compared to $4-14 \%$ when the whole array was coated. ${ }^{[20]}$ The coating should adhere well to the microneedles in order to avoid deposition of the drug on the skin's surface during insertion. This will increase delivery efficiency and is also beneficial from safety perspective. ${ }^{[19]}$ This paper describes a model for coated microneedles, the so-called "coat and pok®5approach $^{[15]}$ as shown in Figure 1.

Martanto et al. ${ }^{[14]}$ studied whether skin permeability to insulin can be enhanced by using a microneedle array while insulin solution is applied topically in a so-called "poke with patch" method ${ }^{[15]}$ Solid microneedles coated with insulin have been applied to diabetic hairless rats whe@ethe decrease in blood glucose levels was significantly greater than in the control case when microneedles were not used. ${ }^{[14]}$ The initial concentration of the drug decreases over time to an ineffectual stage once the drug penetrates into human skin. Therefore, to reach an effective blood concentration, the therapeutic efficacy of drug should be improved by increasing drug administration. ${ }^{[21]}$ Kolli and Banga $^{[22]}$ show that the plasma drug concestration reaches its maximum when using microneedles as compared to passive delivery.

Moreover, our previous work showed the influence of different factors (e.g., microneedle length, surface area of the patch, etc) on the steady-state of blood drug concentration. ${ }^{[23]}$ This studyOMas been administered by presenting a parametric analysis for transdermal delivery of drugs with both high and low molecular weights. A dimensional analysis has been carried our using Buckingham's $\pi$ theorem to determine the functional dependence of blood drug concentration on various parameters. In another study, we have presented a mathematical framework to examine the influence of various coated microneedle dimensions (e.g., micrbonedle thickness, microneedle diameter, etc) on drug permeability. ${ }^{[24]}$ Both the effective skin thickness and permeability have been determined for six microneedle models. The effects on the ratio of permeability $\left(\mathrm{R}_{\mathrm{P}}\right)$ for skin with microneedles to normal skin have also been determined. ${ }^{[24]}$ Motivated by this work, ${ }^{[24]}$ this paper seeks to further study the effects of several geometrical parameters (e.g., microneedle thickness, coating depth, etc) on the insulin bloodl@oncentration profiles. It is rare to find a study that has systematically addressed how 
the microneedle array design parameters influence drug blood concentration profiles from a computational point of view. This work is envisaged to determine the maximum insulin concentration in the blood for various microneedle models, and hence identify the optimum model, if any, for the transdermal drug delivery of insulin.

115

\section{Description of the Modelling Framework}

To model the diffusion process from the coated microneedles into the skin and determine the effects of geometry, six microneedles shapes have been selected as shown in Figure 2. These models have been chosen based on what has been reported in the literature, though they are not andrawn to scale. These models are the same as discussed in our previous work. ${ }^{[24]} \mathrm{A}$ schematic diagram of the developed mathematical framework for insulin transport across the skin via a microneedle array is illustrated in Fig. 1. Solid microneedle arrays are coated by an aqueous solution of insulin molecules which bypass the stratum corneum. ${ }^{[24]}$ Insulin molecules diffuse across viable epidermis until they reach the epidermal-dermal junction wheilethey are absorbed by the microcirculation. In the figure $\mathrm{L}_{\mathrm{u}}$ is the length of the uncoated microneedles, $\mathrm{L}$ is the penetration depth of microneedles, $\mathrm{H}$ is the thickness of the skin after microneedles have been inserted (i.e., the distance between the tip of the microneedle and the blood microcirculation), $\mathrm{h}$ is the epidermis thickness and $\mathrm{S}$ is the microneedle centre-to-centre spacing. Insulin pharmacokinetics are described by a one compartment model (i.e. blood compåtment) with first order elimination kinetics. ${ }^{[5]}$

In this section, the model assumptions in the mathematical framework have been presented. Then, the governing equations of both the diffusive flux and drug concentration in blood along with their initial and boundary conditions have been given and explained in detail.

135

\subsection{Model Assumptions}

When considering the delivery of insulin from the microneedles through the skin, the following assumptions are made in this work: ${ }^{[24]}$

(i) The concentration of insulin in the blood remains low compared the insulin deflocentration on the microneedle, and so the blood is considered to act as a sink. ${ }^{[25]}$

(ii) Skin binding of insulin is assumed to be negligible in the viable skin.

(iii) Insulin metabolism is assumed to be negligible in the viable skin.

(iv) The insulin molecules that diffuse through the viable skin to the interface between viable skin and blood microcirculation are taken up by the microcirculation.

(1A)SDiffusion through the skin is the rate limiting step in the uptake of insulin.

The detailed justifications of these assumptions have been avoided in this paper since they are explained by Davidson et al. ${ }^{[24]}$ However, these assumptions may be briefly explained as below. 
The sfratum corneum is mainly impermeable to insulin due to the intercellular lipid layers. ${ }^{[26]}$ The partition coefficient on the boundary between the viable epidermis and dermis has been assumed to be equal one since both layers (i.e., viable epidermis and dermis) consist mainly of water. ${ }^{[27]}$ Drug partition in the skin was not considered during an intracutaneous injection as the diffusion coefficient was considered more important than the partition coefficient. ${ }^{[28]}$ McAlbister et al. ${ }^{[16]}$ develop a theoretical model to determine the skin permeability of various macromolecules, including insulin, when using microneedle. The permeability was a function of the microneedle dimensions, skin thickness and drug diffusivity and the partition coefficient was not considered. The results agreed well with the experimental data.

Micilonedles have been shown to be a promising technique for achieving effective drug delivery to the blood stream. ${ }^{[29]}$ The drug is absorbed almost completely by the blood vessels once the drug diffuses across the viable epidermis. ${ }^{[5,30]}$ In another study, it has been shown that almost $97 \%$ of the drug is taken up by the blood stream. ${ }^{[31]}$ Furthermore, the blood glucose levels in diabetic hairless rats has been reduced by $80 \%$ when using an array of solid micrb6e edles and an insulin solution placed in contact with the skin. ${ }^{[14]}$ The drop in blood glucose levels due to insulin delivery from microneedles was found to be comparable to that from a hypodermic injection of $0.05-0.5 \mathrm{U}$ insulin $(\mu \mathrm{U} / \mathrm{mL}=0.0417 \mu \mathrm{g} / \mathrm{L})$. These results indicate that microneedles can successfully deliver drugs such as insulin in vivo and the majority of the insulin is absorbed by the blood microcirculation. Ito et al. ${ }^{[13]}$ concluded that insuliñdministered through microneedles was well absorbed by the blood stream.

\subsection{Governing Equations for Diffusive Flux from Coated Microneedles}

The movement of insulin across the viable skin is represented by Fick's second law of diffusion as

$$
\frac{\partial \mathrm{C}}{\partial \mathrm{t}}=\mathrm{D} \frac{\partial^{2} \mathrm{C}}{\partial \mathrm{x}^{2}}
$$

Where $\mathrm{C}\left[\right.$ unit. $\left.\mathrm{m}^{-3}\right]$ is the concentration of insulin, $\mathrm{t}[\mathrm{s}]$ is time, $\mathrm{D}\left[\mathrm{m}^{2} \cdot \mathrm{s}^{-1}\right]$ is the diffusion coefficient of insulin and $x[\mu \mathrm{m}]$ is the path length of insulin molecules in a given skin layer.

In order to solve the above equation, the following Dirichlet type initial and boundary condi8Ons have been imposed.

The initial concentration of insulin in the microneedle coating is

$$
\mathrm{C}=\mathrm{C}_{\mathrm{m} 0}=0 \text { at } \mathrm{L}_{\mathrm{u}}<\mathrm{x}<\mathrm{L} \text { for } \mathrm{t}=0
$$

The boundary conditions for the insulin concentration of coated microneedles are:

At the surface of the coated microneedles, the concentration of insulin is 
$\mathrm{C}=18$ 角 $\quad$ at $\quad \mathrm{L}_{\mathrm{u}}<\mathrm{x}<\mathrm{L} \quad$ for $\mathrm{t}>0$

At the epidermal-dermal junction, the concentration of insulin is

$\mathrm{C}=0 \quad$ at $\mathrm{x}=\mathrm{h}$ for $\mathrm{t}>0$

In equations (2) - (3), $\mathrm{C}_{\mathrm{m} 0}\left[\right.$ unit.m $\left.\mathrm{m}^{-3}\right]$ is the initial concentration of insulin in the microneedle coating, $C_{m}\left[\right.$ unit. $\left.^{-3}\right]$ is the concentration of insulin in the microneedle coating, $L_{u}[\mu \mathrm{m}]$ is the uncdaled microneedle length, $L[\mu \mathrm{m}]$ is the penetration depth of microneedle and $\mathrm{h}[\mu \mathrm{m}]$ is the thickness of epidermis which is defined to be equal to $200 \mu \mathrm{m}$ in this work. ${ }^{[5]}$

Under the above assumptions, the steady state flux of insulin, $\mathrm{J}_{\mathrm{ss}}\left[\right.$ unit. $\left.\mathrm{m}^{-2} \cdot \mathrm{s}^{-1}\right]$, is given as follows: ${ }^{[24,32]}$

$\mathrm{J}_{\mathrm{ss}} 19 \mathrm{BC}_{\mathrm{m}}$

Where $\mathrm{P}\left[\mathrm{m} \cdot \mathrm{s}^{-1}\right]$ is the insulin permeability in the viable skin and $\mathrm{C}_{\mathrm{m}}\left[\right.$ unit. $\left.^{-3}\right]$ is the concentration of insulin in the microneedle coating as mentioned before. In our case we have defined the effective thickness $\mathrm{H}_{\text {eff }}[\mathrm{m}]$ of the skin after microneedles have been inserted as a function of microneedle geometry: ${ }^{[24]}$

$\mathrm{H}_{\mathrm{eff}} 20 \theta \frac{\mathrm{D}_{\mathrm{vs}} \mathrm{C}_{\mathrm{m}}}{\overline{\mathrm{J}}_{\mathrm{ss}}}$

Where $D_{v s}\left[\mathrm{~m}^{2} \cdot \mathrm{s}^{-1}\right]$ is the diffusion coefficient of insulin in the viable skin, $\mathrm{H}_{\text {eff }}$ is the effective skin thickness (i.e., effective path length of molecules in tissue) that insulin molecules can pass in the tissue from coated microneedle which depends on the needle geometry ${ }^{[24]}$ and $\overline{\mathrm{J}}_{\mathrm{SS}}$ [unit. $\mathrm{m}^{-2} \cdot \mathrm{s}^{-1}$ ] is the average steady state flux depending on the needle geometry. The diffusion coeffierent of insulin in the viable skin is assumed to be constant on the basis that the diffusion coefficients in both the viable epidermis and dermis are of the same magnitude. ${ }^{[5]}$

Diffusion of insulin in the skin from the coated microneedles has been modelled in $3 \mathrm{D}$ using FEMLAB $^{\circledR}$, a general partial differential equations solver from Comsol. ${ }^{[33]}$ FEMLAB $^{\circledR}$ is based10h finite element method to solve partial differential equations. This has been done by discretizing or 'meshing', the domain of interestinto a set of small tetrahedral elements.

The flux term determined from the simulations has been integrated over the microcirculation boundary and then divided by the boundary area (i.e. $100 \mu \mathrm{m} \times 100 \mu \mathrm{m}=1 \times 10^{-8} \mathrm{~m}^{2}$ ) to give an a 1 t5ge steady state flux. This value has been used to calculate the effective skin thickness $\left(\mathrm{H}_{\text {eff }}\right)$ as discussed in detail by Davidson et al. ${ }^{[24]}$ This result has been used in the governing equations of blood insulin concentration as has been discussed in the following section.

\subsection{Governing Equations for Insulin Concentration in Blood}


For $2 \mathrm{AB}$ purpose of this work, the insulin concentration in blood after imposing the transdermal drug delivery is given by a one-compartmental pharmacokinetic model: ${ }^{[23,31]}$

$\mathrm{V}_{\mathrm{b}} \frac{\mathrm{dC}_{\mathrm{b}}}{\mathrm{dt}}=\left(\frac{\mathrm{dQ}}{\mathrm{dt}}\right) \mathrm{S}_{\mathrm{a}}-\mathrm{K}_{\mathrm{e}} \mathrm{C}_{\mathrm{b}} \mathrm{V}_{\mathrm{b}}$

Where, $K_{e}$ is the elimination rate constant from the blood compartment, $d Q / d t$ is the penetration rate of insulin through the skin, $S_{a}$ is the surface area of the delivery system (i.e., patcB25f microneedles), $V_{b}$ is the volume of distribution in the blood and $C_{b}$ is the insulin concentration in the blood.

The distance to the blood microcirculation from the skin surface has been reported as 200 $\mu \mathrm{m},{ }^{[5]}$ which is used here as well. The viable skin is modelled as a single domain with a single isotropert diffusion coefficient. The width and length of the square element of skin represents the centre-to-centre spacing of the microneedles, assuming they are in a square pattern as shown in Figure 1. The spacing has been assumed to be $100 \mu \mathrm{m}$, leading to an area for a square element of skin equal to $1 \times 10^{-8} \mathrm{~m}^{2}$. The governing equations (1)-(4) \& (7) have been solved by applying the software, SKIN-CAD ${ }^{\circledR} \cdot{ }^{[34]}$ For brevity, the working principles of this $836 \mathrm{ff}$ ware have been avoided as explained previously. ${ }^{[23,31]}$

This one-compartment model, the simplest pharmacokinetic model, mimics the drug transport behaviour in this case. One assumption that is being made for the above model is that the drug distribution and concentration equilibrium occur rapidly. ${ }^{[35]}$ It is therefore adequate to desczild the pharmacokinetics of drugs that minimally distribute into the body's tissue. ${ }^{[36]}$ As mentioned earlier, the one-compartment model has been used in this paper where we apply the values for the volume of distribution $\left(\mathrm{V}_{\mathrm{b}}\right)$ and the elimination rate constant $\left(\mathrm{K}_{\mathrm{e}}\right)$ obtained from literature for insulin. The one-compartment model with steady state values provides a good approximation, especially for those drugs that distribute and reach steady state quickly. Morz45er, the one-compartment model is more appropriate for a drug when using transdermal drug delivery (e.g., hypodermic injection, microneedle arrays) than for an oral delivery (e.g., pill), which takes time to dissolve, absorb, and distribute into the system. ${ }^{[37]}$ Therefore it is sufficient for the purpose of this work, i.e., to determine the effects of microneedle geometry with insulin as a model drug.

250

\section{Results and Discussions}

In our simulations, the concentration of insulin in blood has been calculated using equation (7). The diffusion coefficients in the viable skin $\left(D_{v s}\right)$ for a number of drugs are not well known. However, insulin, with a molecular weight (MW) of 5800, has been estimated to have

a $D_{2} 5581 \times 10^{-10} \mathrm{~m}^{2} \mathrm{~s}^{-1} \cdot{ }^{[16,38]}$ Average values of the volume of distribution in the blood $\left(\mathrm{V}_{\mathrm{b}}\right)$ 
and the elimination rate constant from the blood compartment $\left(\mathrm{K}_{\mathrm{e}}\right)$ for particular drugs have been documented in literature, as they tend to vary among individuals. However, according to Van Rossum ${ }^{[36]}$ these two parameters have values of $21 \mathrm{~L}$ and $0.46 \mathrm{~h}^{-1}$, respectively. We have defined that the concentration of drug in the microneedle coating $C_{m}$ is $1 \mathrm{unit} / \mathrm{m}^{3}$. Unless othezrose stated, the insertion time of microneedles has been assumed to be four hours.

\subsection{Validation of the developed approach}

We start our discussion by validating the simulations carried out in this mathematical framework. This has been done by comparing the numerical results with the experimental work65 Martanto et al. ${ }^{[14]}$ as shown in Figure 3. It should be noted that only two points were taken in the experimental results. The results show that the simulation results compare adequately with the experimental results. It must be pointed out that the results are for cases when the microneedles have been inserted into diabetic hairless rat. Therefore, an animal skin has been used because of the difficulties of using human skin for various reasons such as ethica70consideration. ${ }^{[39]}$ However, a review has been presented to compare various skins including human and animal skins. ${ }^{[40]}$ In this study, the authors have concluded that mammal skin is a reasonable model to study transdermal delivery in humans. ${ }^{[40]}$

\subsection{Effects of microneedle shapes on insulin distribution in skin}

In opde to determine the effectiveness of transdermal drug delivery using microneedles, the distribution of blood insulin concentrations for each microneedle model has been obtained. In a previous work involving different needle geometries, Lv et al ${ }^{[38]}$ have used a theoretical model to obtain insulin profiles across the skin. They studied both the transient and spatial distribution in the skin tissue as well as in the drug solution. However, they have not cons \&ered the implications of variations in the microneedle geometry. In our study, the distribution of insulin concentration across skin for various microneedles models has been simulated as shown in Figures 4 and 5. As expected, the insulin concentration decreases gradually towards the blood interface due to sink condition there. It seems the most effective model is microneedle model $\mathrm{D}$ as the distribution of insulin concentration (i.e., $0.5 \leq \mathrm{C}_{\text {ins }} \leq 1$ unit $28^{35}$ ) covers most of the skin thickness (i.e., $200 \mu \mathrm{m}$ ). On the other hand, microneedle model $\mathrm{B}$ results in the least distribution of insulin concentration. The uniform distribution is an important factor that can be observed in microneedle models $\mathrm{C}$ and $\mathrm{E}$. In microneedle model $\mathrm{C}$, the drug is distributed mostly on one side. This is due to the cylindrical shape of microneedle with a bevelled tip. However, in microneedle model E, the drug is mainly distralued around the top of the microneedle. This is also due to its arrow-head shape. Back diffusion of insulin has also been observed in all cases.

\subsection{Effects of penetration depth (L)}


To address the implications of the penetration depth (L) on insulin concentration in the blood, the a 95 th of microneedle penetration for microneedle model A (i.e., cylindrical needle at a constant tip angle of $90^{\circ}$ ) has been varied. In addition the penetration depth of the various microneedle model shapes has been varied to examine the influence of $\mathrm{L}$ on the maximum insulin concentration in blood $\left(\mathrm{C}_{\mathrm{b}, \max }\right)$. The performance of the drug delivery process for microneedle arrays could be improved by relating microneedle geometries to the penetration deptBOS The penetration depth of coated microneedles of the same length with various doses was observed. ${ }^{[19]}$ However, the depth of penetration was reduced by increasing the microneedles length while maintaining the same dose by Widera et al. ${ }^{[19]}$ Cormier et al. ${ }^{[41]}$ also found a significant reduction in penetration depth for coated microneedles as compared to uncoated microneedles.

305

The maximum insulin concentration in blood $\left(\mathrm{C}_{\mathrm{b}, \max }\right)$ reaches its highest value for a penetration depth of $180 \mu \mathrm{m}$ with a value of $0.65 \mathrm{ng} / \mathrm{ml}$ as shown in Figure 6. Penetration depth of microneedles in this model represents the depth to which the microneedle penetrates the skin, and as such, does not directly represent the physical length of the microneedle. Apart fromb the variable penetration depth, the dimensions have been used as shown in Table 1. For all microneedle penetration depth cases, the insulin concentration in blood decreases after 4 hours as this has been defined as the length of time the microneedles remain inserted. As the effective skin thickness $\left(\mathrm{H}_{\mathrm{eff}}\right)$ decreases with deeper penetration by the microneedles, ${ }^{[24]}$ the insulin concentration in blood is increased. This implies that by increasing microneedle penetiafion depth, the process of transdermal drug delivery using microneedles has been enhanced significantly.

To further study the effect of penetration depth, the penetration depth (L) of various microneedles models has been changed to observe the effect on the maximum insulin conceztration in blood as shown in Figure 7. Microneedle model $\mathrm{C}$ has not been included due to the similarity in the geometry of this model, and hence the obtained results, with microneedle model A. Microneedle model D is the best model as it has the highest maximum insulin concentration in blood $\left(\mathrm{C}_{\mathrm{b}, \max }\right)$ with a value of $0.73 \mathrm{ng} / \mathrm{ml}$ corresponding to a penetration depth of $180 \mu \mathrm{m}$. The results show that there is a proportional relationship betwees the penetration depth (L) and maximum insulin concentration in blood. As such the penetration depth is a significant factor in determining the maximum insulin concentration in blood.

\subsection{Effects of centre-to-centre spacing of adjacent microneedles (S)}

In tBi30section, the centre-to-centre spacing (S) of microneedle model B (i.e. cone with a constant tip angle of $20.2^{\circ}$ ) has been varied between $75-200 \mu \mathrm{m}$ to analyze the influence of 
this parameter on insulin concentration in blood. Microneedle spacing (pitch) is an important parameter and hence appropriate microneedle spacing should be determined. ${ }^{[42]}$ So far the implications of centre-to-centre spacing have been evaluated in different contexts and rarely on $\mathbf{d} 38$ concentration in blood. For example, the shear stress acting on microneedle tip with microneedle spacing (i.e., varying from $150 \mu \mathrm{m}$ to $600 \mu \mathrm{m}$ ) has been examined by Choi et al. ${ }^{[42]}$ These authors have shown that the optimum microneedle spacing is $450 \mu \mathrm{m}$ as it corresponded to the lowest stress of approximately 34.5 MPa. In this work the centre-tocentre spacing of various insulin-coated microneedle shapes has been varied to study the impact 0 on the maximum insulin concentration in the blood $\left(\mathrm{C}_{\mathrm{b}, \max }\right)$. Closely spaced microneedles are associated with difficulty in insertion due to skin elasticity as reported in a previous study. ${ }^{[43]}$

From Figure 8, the maximum insulin concentration in blood of insulin was $0.31 \mathrm{ng} / \mathrm{ml}$. Apart from 3 fll5e centre-to-centre spacing, the other dimensions have been kept constant as shown in Table 1. As mentioned in the previous results, longer centre-to-centre spacing of microneedles result in higher values of $\mathrm{H}_{\text {eff }}{ }^{[2]}$ The higher effective skin thickness is offset by the increase in the surface area of the microcirculation interface for a given number of microneedles, which tends to increase the flux of drug molecules into the blood stream. Despizip this, increasing microneedle spacing results in generally lower ranges of insulin concentrations.

The centre-to-centre spacing (S) of the microneedle models was varied to study the influence on blood insulin concentrations, as shown in Figure 9. As mentioned previously, microneedle mod $5 \mathrm{~A}$ and microneedle model $\mathrm{C}$ have been found to be indistinguishable so microneedle model $\mathrm{C}$ has not been plotted. Microneedle model $\mathrm{D}$ is the optimum model as it has the highest maximum insulin concentration in blood $\left(\mathrm{C}_{\mathrm{b}, \max }\right)$ with a value of $0.42 \mathrm{ng} / \mathrm{ml}$ for a spacing of $75 \mu \mathrm{m}$. For the range of centre-to-centre spacing studied, the maximum insulin concentration in the blood varies significantly in all microneedle models. The results indicate ther869 an inverse relationship between the centre-to-centre spacing (S) and the maximum insulin concentration in blood.

\subsection{Effects of microneedle diameter (d)}

To assess how the microneedle diameter (d) affects the blood insulin concentration, the diamefter of microneedle model C (i.e., bevelled needle at a constant tip angle of $45^{\circ}$ ) has been varied. In addition, the diameter of each microneedle model was varied to evaluate the influence on the maximum insulin concentration in blood $\left(\mathrm{C}_{\mathrm{b}, \max }\right)$. Khumpuang et al. ${ }^{[44]}$ have claimed that the microneedle diameter should have a diameter greater than the diameter of white blood cell $(\approx 20 \mu \mathrm{m})$ in order to avoid any problem that may arise from blood clogging. 
In gâneral, larger diameters are advantageous in allowing greater mechanical stability ${ }^{[45]}$ as the force required to buckle the microneedle during insertion to the skin increases. ${ }^{[46]}$ Teo et al. ${ }^{[8]}$ have shown that microneedle-mediated drug delivery could be enhanced by increasing microneedle diameters. These results agreed well with the simulations presented by Haider et al.. ${ }^{[47]}$ In another study, it has been shown that microneedle diameter is related to microneedle dens 3 tz̧ 5 i.e., the number of microneedle per unit area. ${ }^{[3]}$

In previous results presented by Davidson et al. ${ }^{[2]}$ it has been shown that varying microneedle diameter does not have a significant influence on the effective skin permeability $\left(\mathrm{P}_{\text {eff }}\right)$. This agrees well with our results as the maximum insulin concentration in blood $\left(\mathrm{C}_{\mathrm{b}, \max }\right)$ for vario6\$diameters did not change significantly and there is a plateau in insulin concentration of approximately $0.34 \mathrm{ng} / \mathrm{ml}$, as shown in Figure 10. This indicates that by increasing microneedle diameter, the process of transdermal drug delivery using microneedles has not been enhanced significantly. Other model dimensions have been kept constant as shown in Table 1.

385

The microneedle diameter (d) of both microneedles model A and $\mathrm{C}$ was varied to observe the influence on insulin concentration as shown in Figure 11. Microneedle model $A$ is the resulted in the highest maximum insulin concentration in blood $\left(\mathrm{C}_{\mathrm{b}, \max }\right)$ with a value of 0.35 $\mathrm{ng} / \mathrm{ml}$ corresponding to a diameter of $60 \mu \mathrm{m}$. However, the maximum insulin concentrations in bBord of both microneedles models were not significantly different, indicating that the maximum insulin concentration in the blood does not strongly depend on the microneedle diameter. Our results suggest that there has been a proportional relationship between microneedle diameter (d) and maximum insulin concentration in blood.

\subsection{Borscts of microneedle insulin coating depth (CD)}

The effect of the depth of insulin coating (CD) on the insulin concentration in the blood requires further study that is beyond the scope of this paper. However, if we assume that $C D$ remains constant during the time that the microneedles are inserted in skin (4 hours in our case), we can perhaps gain an insight on how this affects the blood insulin concentration. Usingthe above assumption, the depth of insulin coating (CD) on microneedle model D (i.e., rocket needle at a constant tip angle of $90^{\circ}$ ) was varied between 40 to $100 \mu \mathrm{m}$ to investigate the influence of this parameter on insulin concentration in the blood. In addition, the coating depth of various microneedle models has been varied to determine the influence of the insulin coating depth on the maximum attainable insulin concentration in blood $\left(\mathrm{C}_{\mathrm{b}, \max }\right)$. In previous worlatise drug coating depth (generally $25 \%-100 \%$ of microneedle length coverage) was examined to study whether uniform drug coating could be achieved. ${ }^{[18]}$ The dose of coated ovalbumin was found to significantly influence the degree of immune response, indicating 
that the size of dose is a significant factor in transdermal drug delivery through microneedle arrays. ${ }^{[19]}$ An earlier study presented by Cormier et al. ${ }^{[41]}$ found that drug delivery efficiency increalid with decreasing coating dose of desmopressin as a model drug. In another study, the amount of ovalbumin coated on microneedles was increased by increasing the coating concentration of ovalbumin which in turn also increased the amount of ovalbumin delivered by the microneedles. ${ }^{[20]}$

Simita5to what has been obtained for increasing microneedle diameter, increasing the coating depth of insulin on the microneedle does not have a very significant effect on the permeability ratio $P_{\text {eff, }}{ }^{[24]}$ As a result, the maximum insulin concentration in blood $\left(C_{b, \max }\right)$ for the range of microneedle diameters being evaluated is almost constant with a value of approximately 0.38 $\mathrm{ng} / \mathrm{ml}$. The results for the effect of microneedle coating depth on the maximum insulin conelentration in blood are shown in Figure 12. All other dimensions have been kept constant as shown in Table 1.

The coating depth (CD) was varied on all microneedles models to determine the effect on the insulin concentration in the blood as shown in Figure 13. Again, the results from microneedle mod $\$ 25 \mathrm{~A}$ and $\mathrm{C}$ are indistinguishable and hence microneedle $\mathrm{C}$ has been omitted from the results. Microneedle model D resulted in the highest maximum insulin concentration in blood $\mathrm{C}_{\mathrm{b}, \max }$ with a value of $0.38 \mathrm{ng} / \mathrm{ml}$ corresponding to a coating depth of $100 \mu \mathrm{m}$. However, over the range of coating depth examined the maximum insulin concentration did not change significantly. This indicates that the maximum blood insulin concentration does not depend signiffisently on the coating depth.

\subsection{Effects of microneedle thickness (T)}

The thickness (T) of microneedle model E (i.e., arrow needle at a constant tip angle of $73.8^{\circ}$ ) was varied for insulin between 25 to $75 \mu \mathrm{m}$. In addition, the thickness of various microneedle mod $\$ B 5$ coated with insulin has been varied to examine the influence of the microneedle thickness on the maximum insulin concentration in blood $\left(\mathrm{C}_{\mathrm{b}, \max }\right)$. Microneedle thickness has been considered a key factor due to its influence on the force required to fracture the microneedle. ${ }^{[43]}$ In one study, it was observed that with large microneedle thickness, the margin of safety (i.e. ratio between microneedle fracture and skin insertion force) reached its high 440 value. Rajaraman and Henderson ${ }^{[48]}$ have considered the thickness as an important dimension since it determines the aspect ratio of their fabrication process.

The results shown in Figure 14 indicate that by increasing the thickness of the microneedles, the maximum insulin concentration in blood $\left(\mathrm{C}_{\mathrm{b}, \max }\right)$ can be increased. However, over the rang $₫ 45 f$ thicknesses used, the range of $C_{b, \max }$ is generally smaller when compared to the range 
that has been obtained by varying both penetration depth of microneedle and centre-to-centre spacing of microneedles. This is because increasing microneedle thickness results in less significant increases in $\mathrm{P}_{\text {eff }}$, as shown previously ${ }^{[24]}$. All other dimensions have been kept the same as shown in Table 1.

450

The microneedle thickness (T) of microneedles models D-F was varied to determine the influence on the blood insulin concentration as shown in Figure 15. It must be noted that the microneedle thickness is only important for in-plane manufactured microneedles (i.e., microneedles models D-F). Microneedle model D results in the highest maximum insulin conctinfration in blood $\left(\mathrm{C}_{\mathrm{b}, \max }\right)$ with a value of $0.41 \mathrm{ng} / \mathrm{ml}$ corresponding to a thickness of 75 $\mu \mathrm{m}$. Over the range of microneedles thicknesses chosen, the maximum insulin concentration was only slightly changed, indicating that it is a relatively weak function of the microneedle thickness. The results indicate a proportional relationship between microneedle thickness (T) and the maximum insulin concentration in blood.

460

3.8 Effects of the number of microneedles in the array $(\mathrm{N})$

To systematically address the implications of the number of microneedles in the array $(\mathrm{N})$ on insulin concentration in the blood, the number of microneedles in the arrays for microneedle model F (i.e., wedge needle at a constant tip angle of $20.2^{\circ}$ ) has been varied. In addition, the num $\$ 65$ of microneedles in the arrays of each microneedle model was also been varied to examine the effect on the maximum insulin concentration in blood $\left(\mathrm{C}_{\mathrm{b}, \max }\right)$. Since microneedles were first introduced, varying numbers of microneedles per array have been fabricated. Examples of microneedle number in literature vary between $9^{[49]}$ and $657 .{ }^{[19]}$ According to Stoeber and Liepmann, ${ }^{[3]}$ the efficiency of transdermal drug delivery improves with4inereasing numbers of microneedles in the array. Park et al. ${ }^{[50]}$ have claimed that by increasing the number of microneedles in the arrays, skin permeability increases. Gill and Prausnitz ${ }^{[18]}$ have found that by increasing the number of microneedles in the arrays, it was possible to increase the amount riboflavin coated to the array. On the other hand, the delivery of a given antigen dose did not depend on the number of microneedles in the array. ${ }^{[19]}$ Ito et al. ${ }^{[13} 47$ ave shown that plasma glucose level does not change significantly by reducing the number of microneedles from 5 to 1 microneedle. Gardeniers et al. ${ }^{[51]}$ have demonstrated that plasma concentration of diclofenac increases by increasing the number of microneedles.

To obtain a theoretical perspective on the influence of the number of microneedles, the num\$80 was varied for model F. From Figure 1(b), the surface area for one needle is equal to the width multiply by the length $\left(1 \times 10^{-8} \mathrm{~m}^{2}\right.$ in the present case). Therefore, the total surface area of a given patch $\left(S_{a}\right)$ has been defined to be the surface area for one needle 
multiplies by the number of microneedles. This value has been used as an input parameter in SKIN-CAD ${ }^{\circledR}$ to describe patch surface area. We have also defined that the effective skin thickires for a patch to be the same as that for one micro-needle. All other dimensions have been kept constant as shown in Table 1. As expected, Figure 16 confirms that by increasing the number of microneedles, the maximum insulin concentration in blood $\left(\mathrm{C}_{\mathrm{b}, \max }\right)$ also increases. This is expected as $S_{a}$ is a linear function of the number of microneedles and in turn the insulin concentration in blood $C_{b}$ is a linear function of $S_{a}$.

490

The number of microneedles in the array $(\mathrm{N})$ of each microneedle models was varied to study the influence on blood insulin concentration of coated insulin as shown in Figure 17. As explained previously, microneedle model $\mathrm{A}$ and microneedle model $\mathrm{C}$ have been found to be indistinguishable so the results for microneedle model $\mathrm{C}$ have not been plotted. Microneedle mod\$9D results in the highest maximum insulin concentration in blood $\left(\mathrm{C}_{\mathrm{b}, \max }\right)$ with a value of $1.9 \mathrm{ng} / \mathrm{ml}$ corresponding to a microneedle number of 500 . For the range of $\mathrm{N}$ studied, the maximum insulin concentration in the blood varied significantly, indicating that the maximum concentration is a very strong function of microneedle number. Indeed, microneedle number appears to be the most significant parameter of those examined. The results indicate a prop 5000 al relationship between the number of microneedles in the array $(\mathrm{N})$ and maximum insulin concentration in blood.

\section{Conclusion}

Insulin was chosen as a model drug to study the effects of microneedle geometry on blood conconfration profiles. A mathematical framework has been presented to this effect. The maximum insulin concentration in blood $\left(\mathrm{C}_{\mathrm{b}, \max }\right)$ was also calculated for various microneedle models. The influence of microneedle geometry has been discussed and compared for various microneedles models. However, as many parameters determine insulin transport from microneedle arrays, there is scope to further study these issues in future work.

510

For the purpose of this paper a range of microneedle models have been utilised. The distribution of insulin across skin for all the microneedles models has been investigated. For the geometrical parameters chosen, it seems that the most effective microneedle model in terms of the distribution of insulin concentration is the rocket needle that has a constant tip $\operatorname{ang} 1516 \mathrm{f} 90^{\circ}$ (i.e., microneedle model D). Also, it has been found that the number of microneedles in an array is the most significant factor in determining maximum insulin concentration in blood $\left(\mathrm{C}_{\mathrm{b}, \max }\right)$. This was expected as the insulin concentration in blood has a proportional relationship with the surface area of the array which is in turn proportional to the number of microneedles in the array. Penetration depth of the microneedle, centre-to-centre spac5pgg and microneedle thickness had a less significant effect on the maximum insulin 
concentration in the blood. No differences have been observed in the maximum insulin concentration in the blood by varying the other microneedle parameters (i.e. coating depth of the microneedles, microneedle diameter). Moreover, it has been observed that the optimum microneedle model in terms of varying microneedle diameter was microneedle model A. Mic 5 hedle model D was the best model in terms of the other microneedle dimensions.

\section{Acknowledgment}

This work was funded by the Ministry of Interior (MOI), Kuwait. One of the authors (Barrak Al-Qallaf) would like to thank Dr. Naser Zamanan and Mr. Abdullah Zakariya for helpful disc63800ns on the paper.

\section{Nomenclature}

C concentration of insulin (unit $/ \mathrm{m}^{3}$ )

$\mathrm{C}_{\mathrm{b}} \quad$ insulin concentration in the blood $(\mathrm{ng} / \mathrm{ml})$

$\mathrm{C}_{\mathrm{b}, \mathrm{m} \text { 5x }} 35$ maximum insulin concentration in the blood ( $\left.\mathrm{ng} / \mathrm{ml}\right)$

$\mathrm{CD}$ depth of insulin coating $(\mu \mathrm{m})$

$\mathrm{C}_{\mathrm{m}} \quad$ concentration of insulin in the microneedle coating (unit $/ \mathrm{m}^{3}$ )

$\mathrm{C}_{\mathrm{m} 0} \quad$ initial concentration of insulin in the microneedle (unit $/ \mathrm{m}^{3}$ )

D diffusion coefficient $\left(\mathrm{m}^{2} / \mathrm{s}\right)$

d 540microneedle diameter $(\mu \mathrm{m})$

$\mathrm{D}_{\mathrm{vs}} \quad$ diffusion coefficient of insulin in the viable skin

$\mathrm{h} \quad$ epidermis thickness $(\mu \mathrm{m})$

$\mathrm{H} \quad$ thickness of the skin after inserting the microneedle $(\mu \mathrm{m})$

$\mathrm{H}_{\text {eff }} \quad$ effective thickness of the skin after inserting the microneedle $(\mu \mathrm{m})$

$\overline{\mathrm{J}}_{\mathrm{ss}}$ 545average steady state flux (unit $/ \mathrm{m}^{2} \mathrm{~s}$ )

$\mathrm{K}_{\mathrm{e}} \quad$ elimination rate constant from the blood compartment $(1 / \mathrm{h})$

L penetration depth of microneedles $(\mu \mathrm{m})$

$\mathrm{L}_{\mathrm{u}} \quad$ length of the uncoated microneedles $(\mu \mathrm{m})$

$\mathrm{N}$ number of microneedles in the array (-)

P 550permeability of insulin in skin $(\mathrm{m} / \mathrm{s})$

$\mathrm{P}_{\text {eff }} \quad$ effective skin permeability of drug $(\mathrm{m} / \mathrm{s})$

S centre-to-centre spacing of microneedles $(\mu \mathrm{m})$

$\mathrm{S}_{\mathrm{a}} \quad$ surface area of the microneedle patch $\left(\mathrm{m}^{2}\right)$

$\mathrm{t}$ time (s)

$\mathrm{T} \quad$ 555microneedle thickness $(\mu \mathrm{m})$

$\mathrm{V}_{\mathrm{b}} \quad$ volume of distribution in the blood (L)

$\mathrm{x} \quad$ path length of insulin molecules in a given skin layer $(\mu \mathrm{m})$ 
$\mathrm{dQ} / \mathrm{dt} \quad$ penetration rate of insulin through the skin $\left(\mu \mathrm{g} / \mathrm{cm}^{2} \mathrm{~h}\right)$

\section{Reffetences}

[1] E.V. Mukerjee, S.D. Collins, R.R. Issroff, R.L. Smith. Sens. Actuators A, 2004; 114, $267-$ 275.

[2] Y. Xie, B. Xu, Y. Gao. Nanomed. Nanotechnol. Biol. Med., 2005; 1, 184-190. 565

[3] B. Stoeber, D. Liepmann. J. Microelectromech. Syst., 2005; 14, 472-479.

[4] W. Martanto. Ph.D. Thesis, Georgia Institute of Technology, USA, 2005.

[5] K.70ojo. J. Chem. Eng. Jpn., 1987; 20, 300-308.

[6] D. Van Der Merwe. Ph.D. Thesis. North Carolina State University, USA, 2005.

[7] Y. Lee, K. Hwang. Surg. Radiol. Anat., 2002; 24, 183-189. 575

[8] M.A.L. Teo, C. Shearwood,K.C. Ng, J. Lu, S. Moochhala. Biomed. Microdevices, 2005; 7, 47-52.

[9] M.A.L. Teo, C. Shearwood, K.C. Ng, J. Lu, S. Moochhala. Mater. Sci. Eng. A, 2006; 132, $151-589$.

[10] S.P Davis, W. Martanto, M.G. Allen, M.R. Prausnitz. IEEE Trans. Biomed. Eng., 2005; 52, 909-915.

[11]58.\$. Capes, D. Hunt, K. Malmberg, P. Pathak, H.C. Gerstein. Stroke, 2001; 32, 24262432.

[12] L. Nordquist, N. Roxhed, P. Griss, G. Stemme. Pharm. Res., 2007; 24, 1381-1388.

[13]599.0Ito, E. Hagiwara, A. Saeki, N. Sugioka, K. Takada. Eur. J. Pharm. Sci., 2006; 29, 8288 .

[14] W. Martanto, S.P. Davis, N.R. Holiday, J. Wang, H.S. Gill, M.R. Prausnitz. Pharm. Res., 2004; 21, 947-952. 
[15] M.R. Prausnitz. Adv. Drug Delivery Rev., 2004; 56, 581-587.

[16] D.V. McAllister, P.M. Wang, S.P. Davis, J.H. Park, P.J. Canatella, M.G. Allen, M.R. Prausnitz. PNAS, 2003; 100, 13755-13760.

600

[17] P.M. Wang, M. Cornwell, J. Hill, M.R. Prausnitz. J. Invest. Dermatol., 2006; 126, 1080 1087.

[18] H.S. Gill, M.R. Prausnitz. J. Controlled Release, 2007; 117, 227-237. 605

[19] G. Widera, J. Johnson, L. Kim, L. Libiran, K. Nyam, P. Daddona, M. Cormier. Vaccine, 2006; 24, 1653-1664.

[20] J.A. Matriano, M. Cormier, J. Johnson, W.A. Young, M. Buttery, K. Nyam, P.E. Dad6d0a. Pharm. Res., 2002; 19, 63-70.

[21] J.T Santini, A.C. Richards, R.A. Scheidt, M.J. Cima, R.S. Langer. Ann. Med., 2000; 32, 377-379.

[22]60.S. Kolli, A.K. Banga. Pharm. Res., 2007; 25, 104-113.

[23] B. Al-Qallaf, D.B. Das, D. Mori, Z.F. Cui. Phil. Trans. R. Soc. A, 2007; 365, 2951-2967.

[24] A. Davidson, B. Al-Qallaf, D.B. Das. Chem. Eng. Res. Des., 2008; 86, 1196-1206. 620

[25] D. Mori, H. Kawamata, K. Tojo. J. Chem. Eng. Jpn., 2003; 36, 45-48.

[26] N. Sadrzadeh, M.J. Glembourtt, C.L. Stevenson. J. Pharm. Sci., 2007; 96, 1925-1954.

[27]62SV. Ranade. J. Clin. Pharmacol., 1991; 31, 401-418.

[28] D. Yoshida, H. Todo, T. Hasegawa, K. Sugibayashi. Eur. J. Pharm. Sci., 2008; 35, 5-11

[29] M. Yang, J.D. Zahn. Biomed. Microdevices, 2004; 6, 177-182.

630

[30] A. Zesch, H. Schaefer. Arch. Derm. Res., 1975; 252, 245-256. 
[31] K. Tojo. Mathematical models of transdermal and topical drug delivery, Biocom Systems Inc.: Japan, 2005.

635

[32] G.P. Moss, J.C. Dearden, H. Patel, M.T.D. Cronin. Toxicol. in Vitro, 2002; 16, 299-317.

[33] A.B. Comsol..FEMLAB ${ }^{\circledR}$ 3. Multiphysics modelling, Stockholm, Sweden, 2005.

[34] 2006.

[35] X. Xu, C.P. Weisel. J. Exposure Anal. Environ. Epidemiol., 2005; 15, 6-16.

[36]645 an Rossum. Kinetics of Drug Action, Springer-Verlag: Berlin, 1977.

[37] A.B. Shiflet, G.W. Shiflet. Introduction to computational science: modeling and simulation for the sciences, Princeton University Press: South Carolina, 2006.

[38]68.G. Lv, J. Liu, Y.H. Gao, B. Xu. J. Micromech. Microeng., 2006; 16, 2492-2501.

[39] P. Sartorelli, H.R. Anderson, J. Angerer, J. Corish, H. Drexler, T. Goen, P. Griffin, S.A.M. Hotchkiss, F. Larese, L. Montomoli, J. Perkins, M. Schmelz, J. van de Sandt, F. Williams. Environ. Toxicol. Pharmacol., 2000; 8, 133-152.

655

[40] B. S. Godin, E. Touitou. Adv. Drug Delivery Rev, 2007; 59, 1152-1161.

[41] M. Cormier, B. Johnson, M. Ameri, K. Nyam, L. Libiran, D.D. Zhang, P. Daddona. J. Controlled Release, 2004; 97, 503-511.

660

[42] J.W. Choi, I.B. Park, Y.M. Ha, M.G. Jung, S.W. Lee, S.H. Lee. In: Proceedings of International Joint Conference, October 18-21, Bexco, Pusan, Korea, 2006.

[43] S.P. Davis, B.J. Landis, Z.H. Adams, M.G. Allen, M.R. Prausnitz. J. Biomech., 2004; 37, 1155615163.

[44] S. Khumpuang, M. Horade, K. Fujioka, S. Sugiyama. Memoirs of the SR Centre Ritsumeikan University, No. 7, April, pp.25-30, Japan, 2005.

[45]6A.0Ovsianikov, B. Chichkov. Int. J. Appl. Ceram. Technol., 2007; 4, 22-29. 
[46] J.H. Park, Y.K. Yoon, S.O. Choi, M.R. Prausnitz, M.G. Allen. IEEE Trans. Biomed. Eng., 2007; 54, 903-913.

[47]61.5Haider, R.J. Pettis, N. Davison, R. Clarke, J.D. Zahn. In: Proceedings of the 25th Annual Meeting of the American Society of Biomechanics, August, San Diego, California, USA (Abstract), 2001.

[48] S. Rajaraman, H.T. Henderson. Sens. Actuators B, 2005; 105, 443-448. 680

[49] X.M. Wu, H. Todo, K. Sugibayashi. J. Controlled Release, 2007; 118, 189-195.

[50] J.H. Park, M.G. Allen, M.R. Prausnitz. J. Controlled Release 2005; 104, 51-66.

[51]685J.G.E. Gardeniers, R. Luttge, E.J.W. Berenschot, M.J. de Boer, S.Y. Yeshurun, M. Hefetz, R.V. Oever, A. van den Berg. J. Microelectromech. Syst, 2003; 12, 855-862. 
Table 1. The standard design parameters of each microneedle model (Figure 1)

\begin{tabular}{|c|c|c|c|c|c|c|c|c|}
\hline Model & $\begin{array}{c}\text { Penetration } \\
\text { Depth }^{*} \\
(\mu \mathrm{m})\end{array}$ & $\begin{array}{c}\text { Diameter } \\
(\mu \mathrm{m})\end{array}$ & \multicolumn{2}{|c|}{$\begin{array}{l}\text { Width } \\
(\mu \mathrm{m})\end{array}$} & $\begin{array}{c}\text { Thickness } \\
(\mu \mathrm{m})\end{array}$ & $\begin{array}{c}\text { Spacing } \\
(\mu \mathrm{m})\end{array}$ & $\begin{array}{c}\text { Coating } \\
\text { Depth }^{\#} \\
(\mu \mathrm{m})\end{array}$ & $\begin{array}{c}\text { Number } \\
\text { in array } \\
(-)\end{array}$ \\
\hline A & 140 & 50 & \multicolumn{2}{|c|}{-} & - & 100 & 100 & 100 \\
\hline $\mathrm{B}$ & 140 & 50(at base) & \multicolumn{2}{|c|}{ - } & - & 100 & 100 & 100 \\
\hline $\mathrm{C}$ & 140 & 50 & \multicolumn{2}{|c|}{-} & - & 100 & 100 & 100 \\
\hline $\mathrm{D}$ & 140 & - & \multicolumn{2}{|c|}{50} & 35 & 100 & 100 & 100 \\
\hline \multirow[t]{2}{*}{$\mathrm{E}$} & \multirow[t]{2}{*}{140} & \multirow[t]{2}{*}{ - } & shaft & tip & \multirow[t]{2}{*}{35} & \multirow[t]{2}{*}{100} & \multirow[t]{2}{*}{100} & \multirow[t]{2}{*}{100} \\
\hline & & & 30 & 60 & & & & \\
\hline $\mathrm{F}$ & 140 & - & \multicolumn{2}{|c|}{50} & 35 & 100 & 100 & 100 \\
\hline
\end{tabular}

*Penetration depths (L) of all microneedles models represent the depth to which the microneedles penetrate the skin, and as such, does not directly represent the physical length of the microneedle as shown in Figure 1.

\# The difference between the penetration depth (L) and the length of the uncoated microneedles $\left(\mathrm{L}_{\mathrm{u}}\right)$ is the coating depth $\left(\mathrm{L}-\mathrm{L}_{\mathrm{u}}\right)$ 
(a)

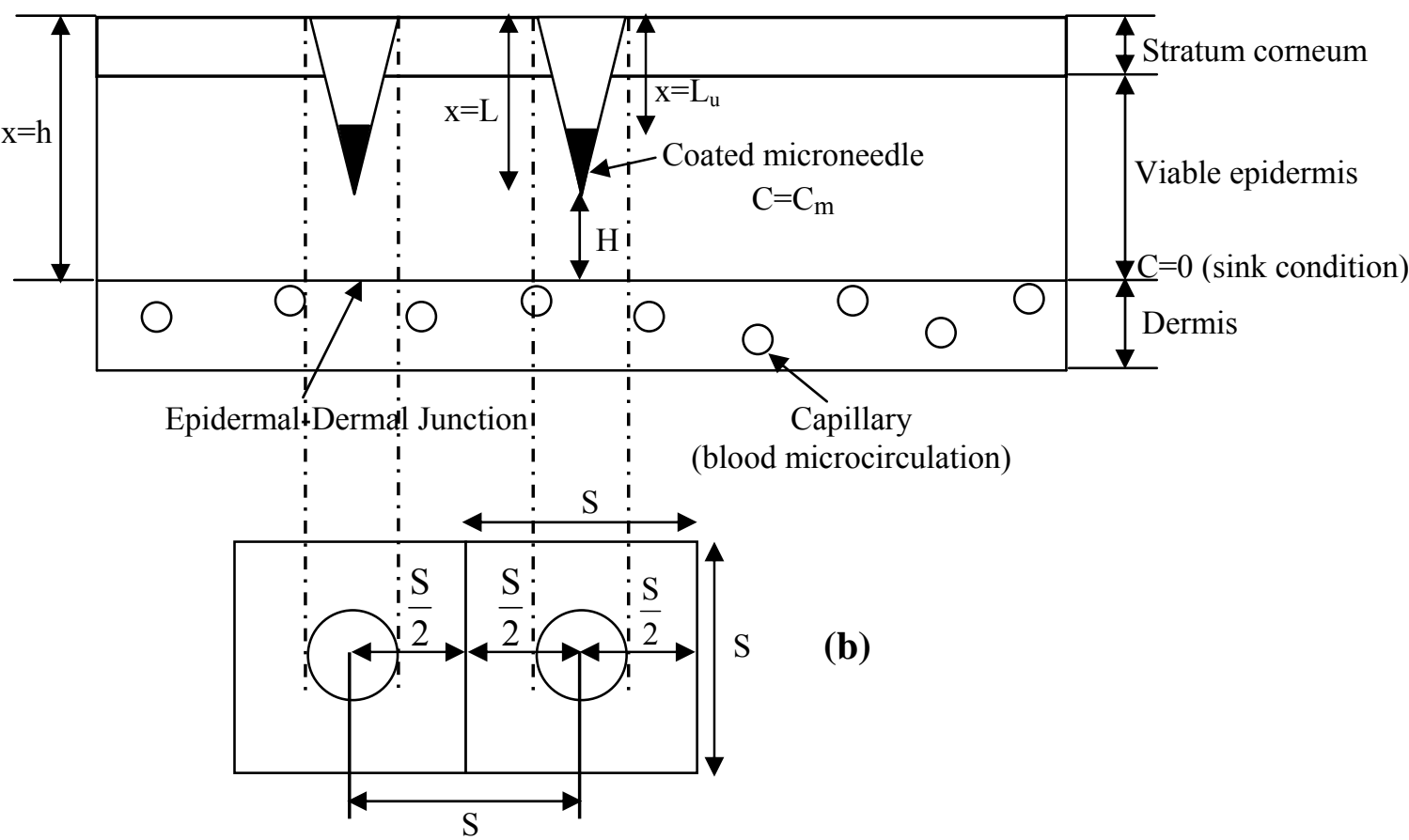

Figure 1. Schematic of coated microneedles for transdermal insulin delivery: (a) side view, (b) top view. $\mathrm{H}$ is the thickness of the skin after microneedles have been inserted (i.e., the distance between the tip of the microneedle and the blood microcirculation), $h$ is the epidermis thickness, $\mathrm{L}$ is the penetration depth of microneedles, $\mathrm{L}_{u}$ is the length of the uncoated microneedles and $\mathrm{S}$ is the centre-to-centre spacing. 


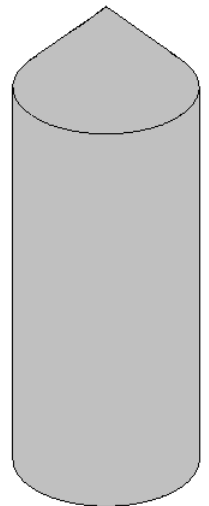

A

Cylindrical needle

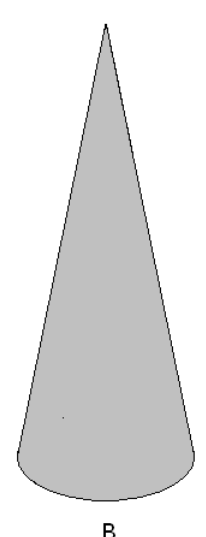

Conical needle

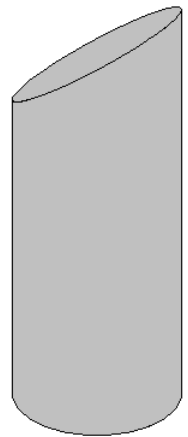

C

Bevelled needle

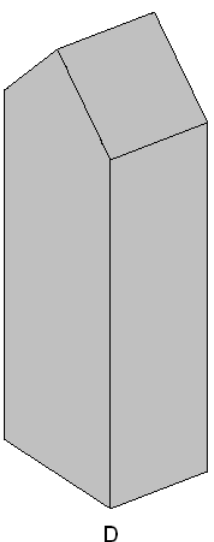

Rocket needle

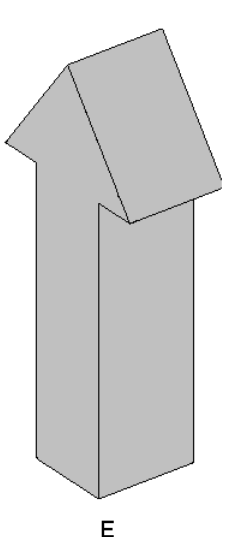

Arrow needle

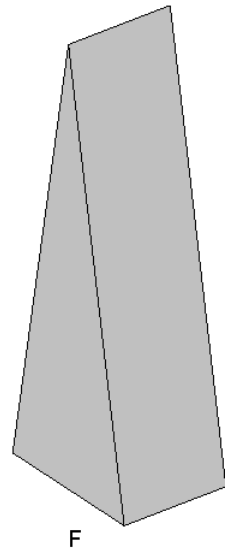

Wedge needle

Figure 2. The six microneedle models used in this study adopted from Davidson et al. ${ }^{[24]}$. 


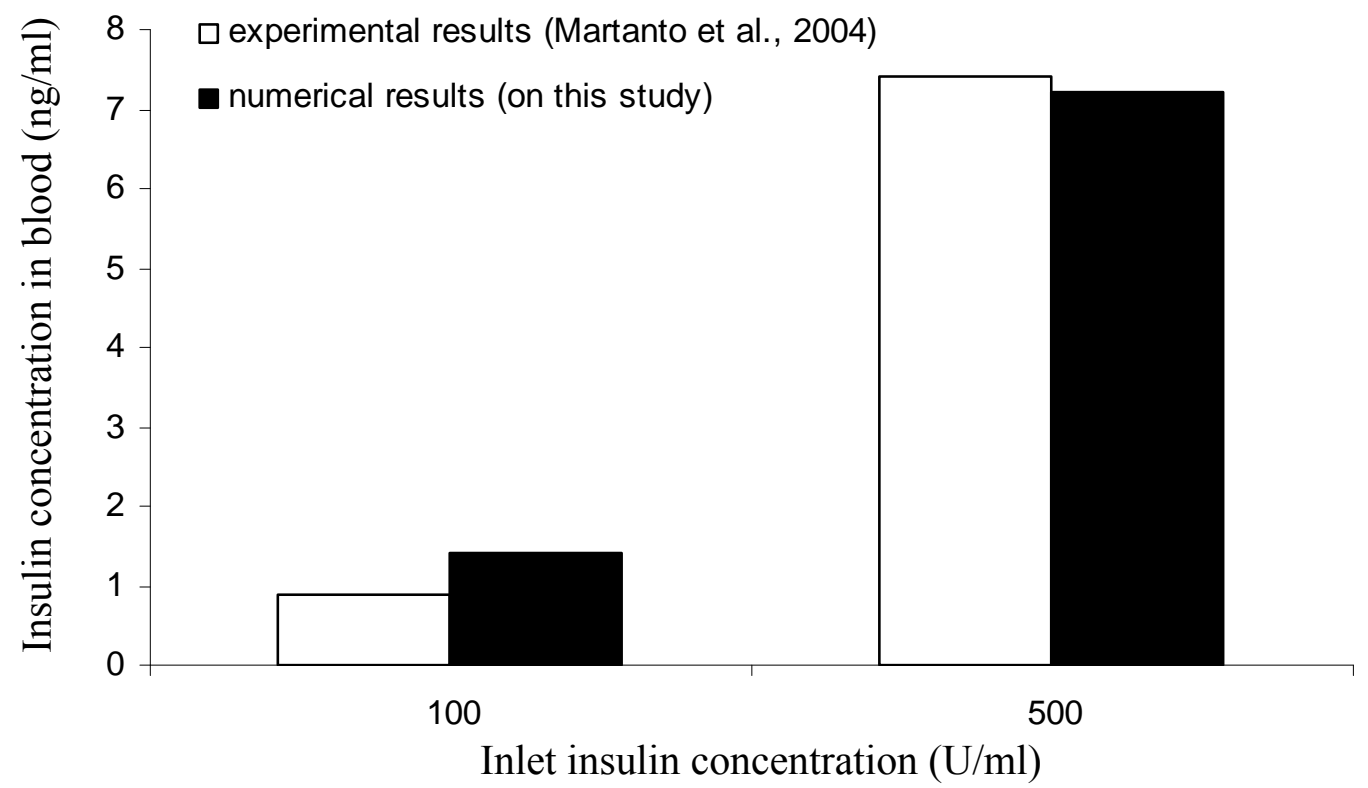

Figure 3. Comparison of the simulated blood concentration profile of insulin after applying transdermal delivery by microneedle model $\mathrm{F}$ (black column) and the experimental results (blank column) assuming the insertion time of microneedles to be four hours. 


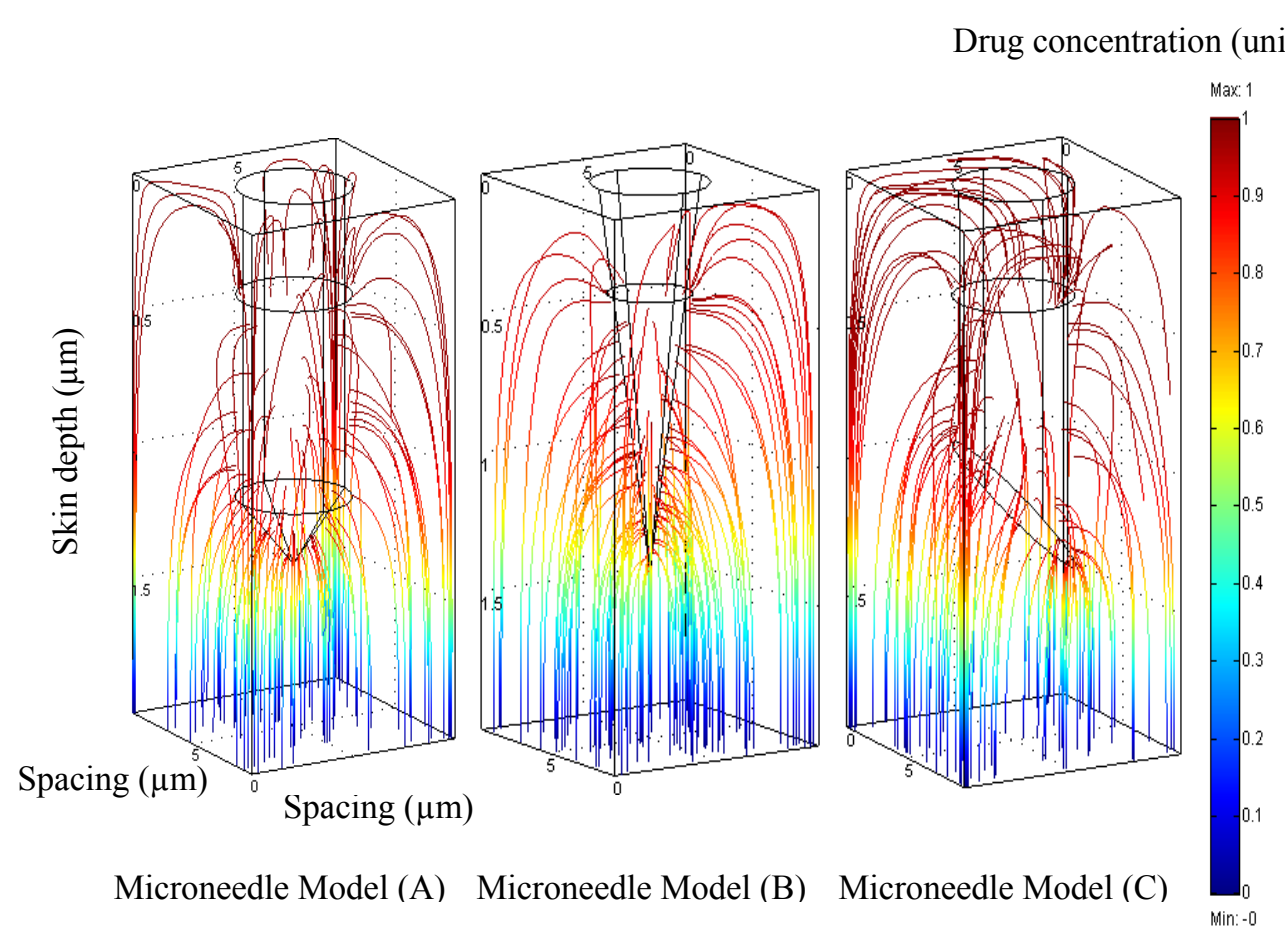

Figure 4. Distribution of Insulin in skin for microneedle models (A), (B) and (C) (penetration depth is $140 \mu \mathrm{m}$ and all the remaining dimensions with their standard values as mentioned in Table 1). 
Drug concentration (unit $\left./ \mathrm{m}^{3}\right)$
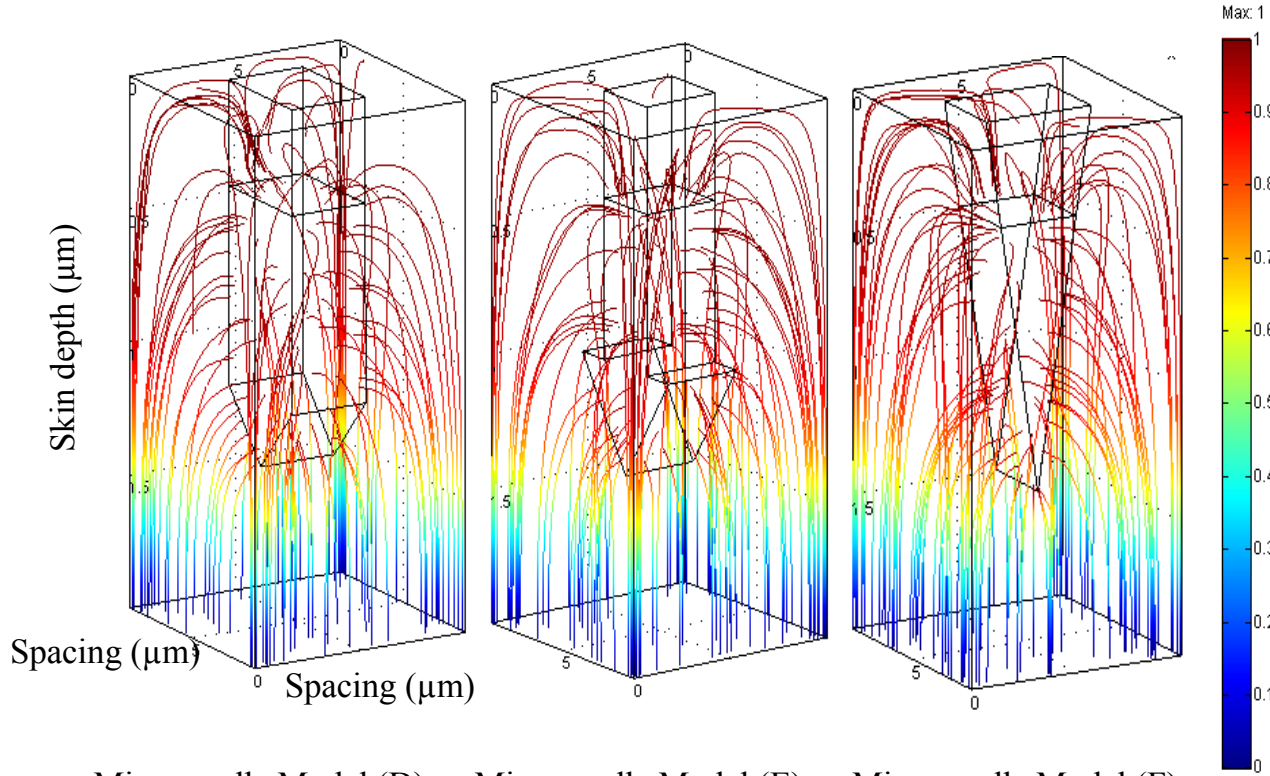

Microneedle Model (D)

Microneedle Model (E)

Microneedle Model (F)

Min:-0

Figure 5. Distribution of Insulin in skin for microneedle models (D), (E) and (F) (penetration depth is $140 \mu \mathrm{m}$ and all the remaining dimensions with their standard values as mentioned in Table 1). 


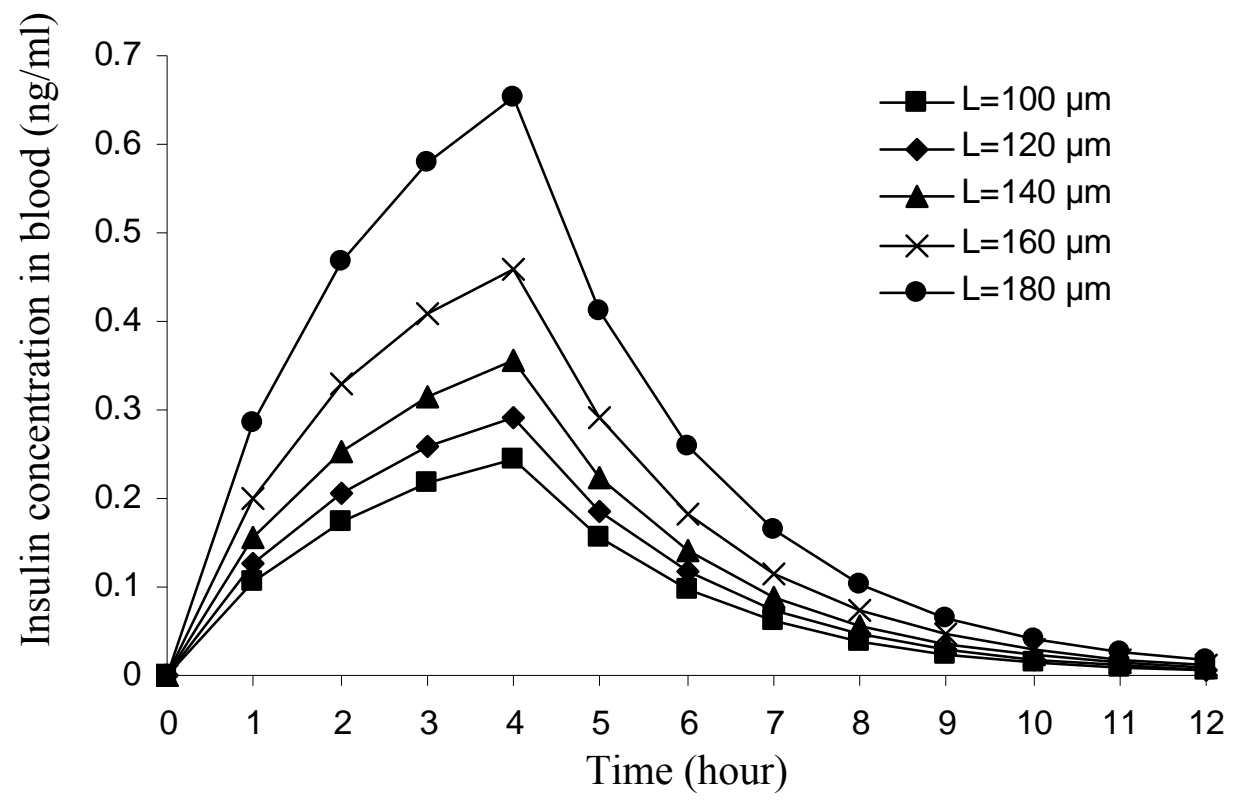

Figure 6. Influence of the penetration depth (L) of microneedle model (A) on insulin concentration in blood, assuming that the insertion time of microneedles is four hours. 


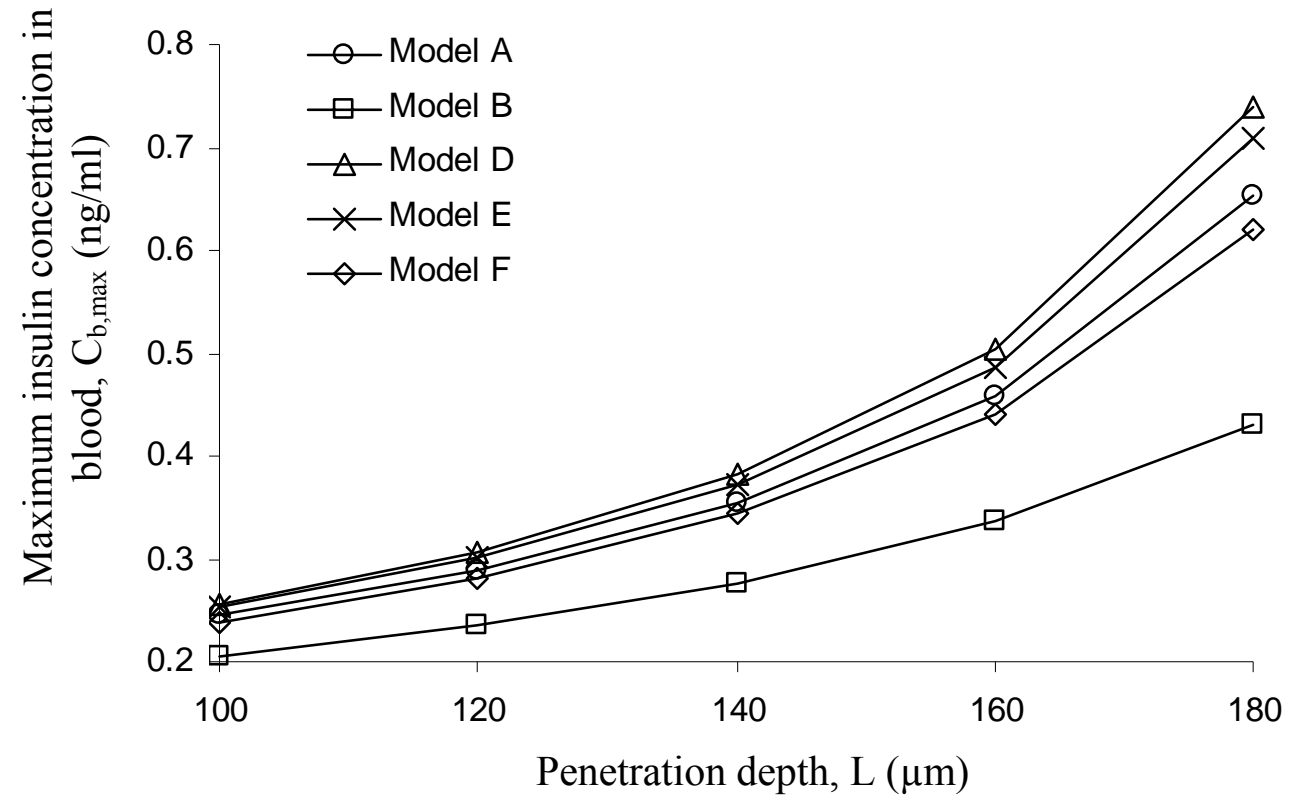

Figure 7. Influence of the penetration depth (L) of various microneedles models, coated with insulin, on the maximum insulin concentration in blood $\left(\mathrm{C}_{\mathrm{b}, \max }\right)$, assuming that the insertion time of microneedles is four hours (the results of microneedle model $\mathrm{C}$ are not included in the figure as they are very similar to the results of microneedle model A). 


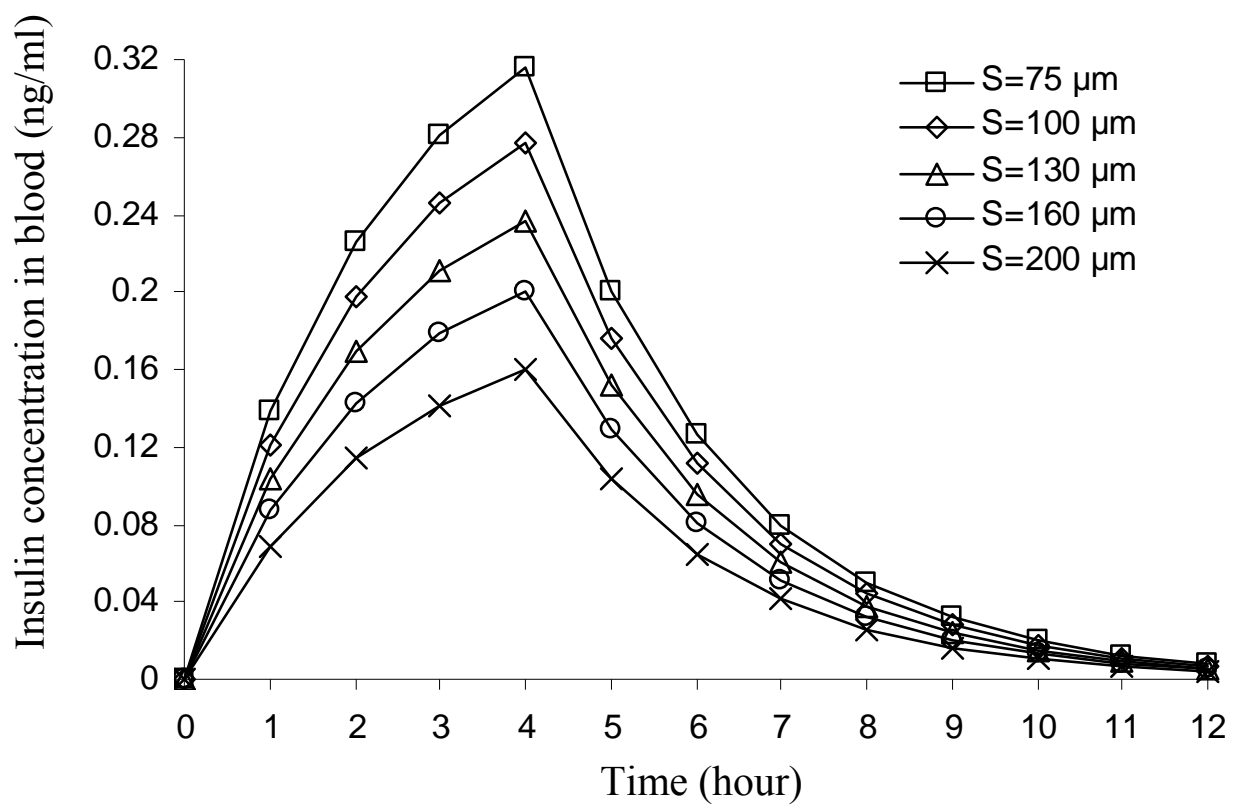

Figure 8. Influence of the centre-to-centre spacing (S) of microneedle model (B) on insulin concentration in blood, assuming that the insertion time of microneedles is four hours. 


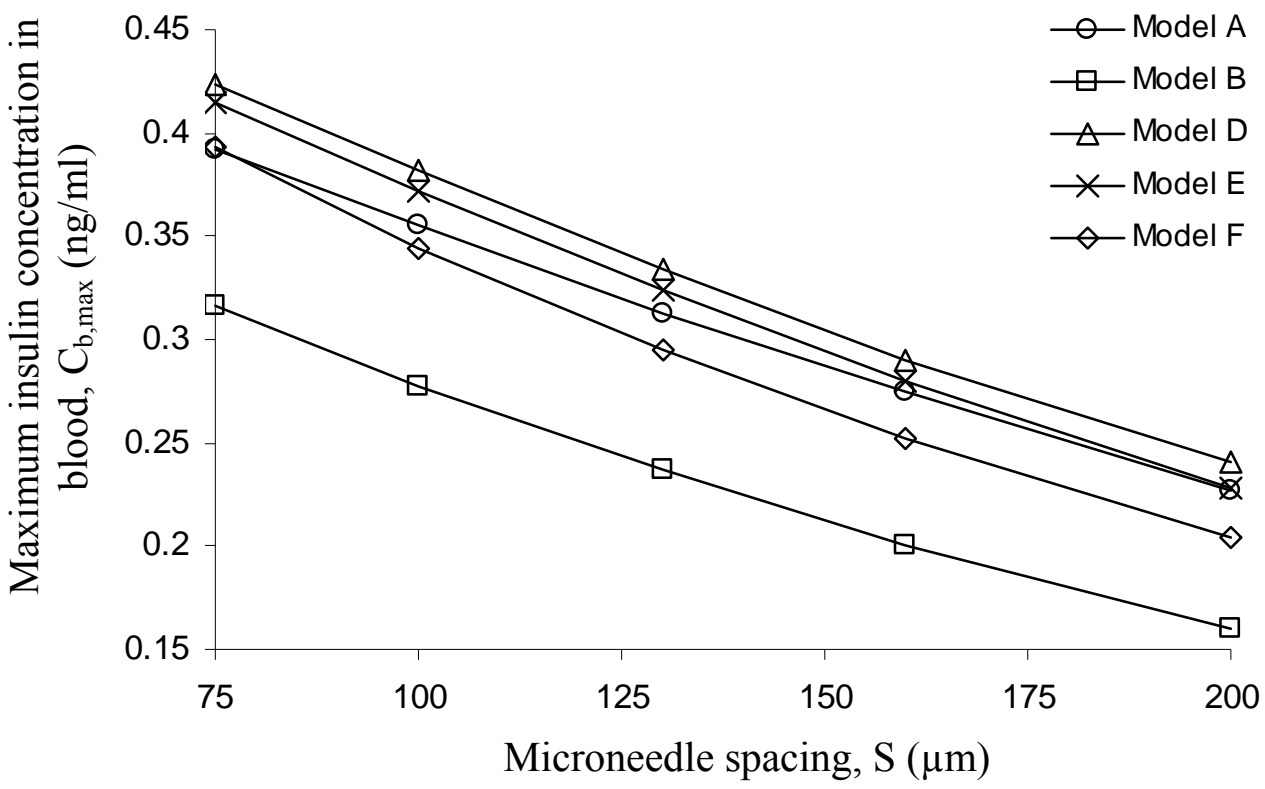

Figure 9. Influence of the centre-to-centre spacing (S) of various microneedles models, coated with insulin, on the maximum insulin concentration in blood $\left(\mathrm{C}_{\mathrm{b}, \max }\right)$, assuming that the insertion time of microneedles is four hours (the results of microneedle model $\mathrm{C}$ are not included in the figure as they are very similar to the results of microneedle model A). 


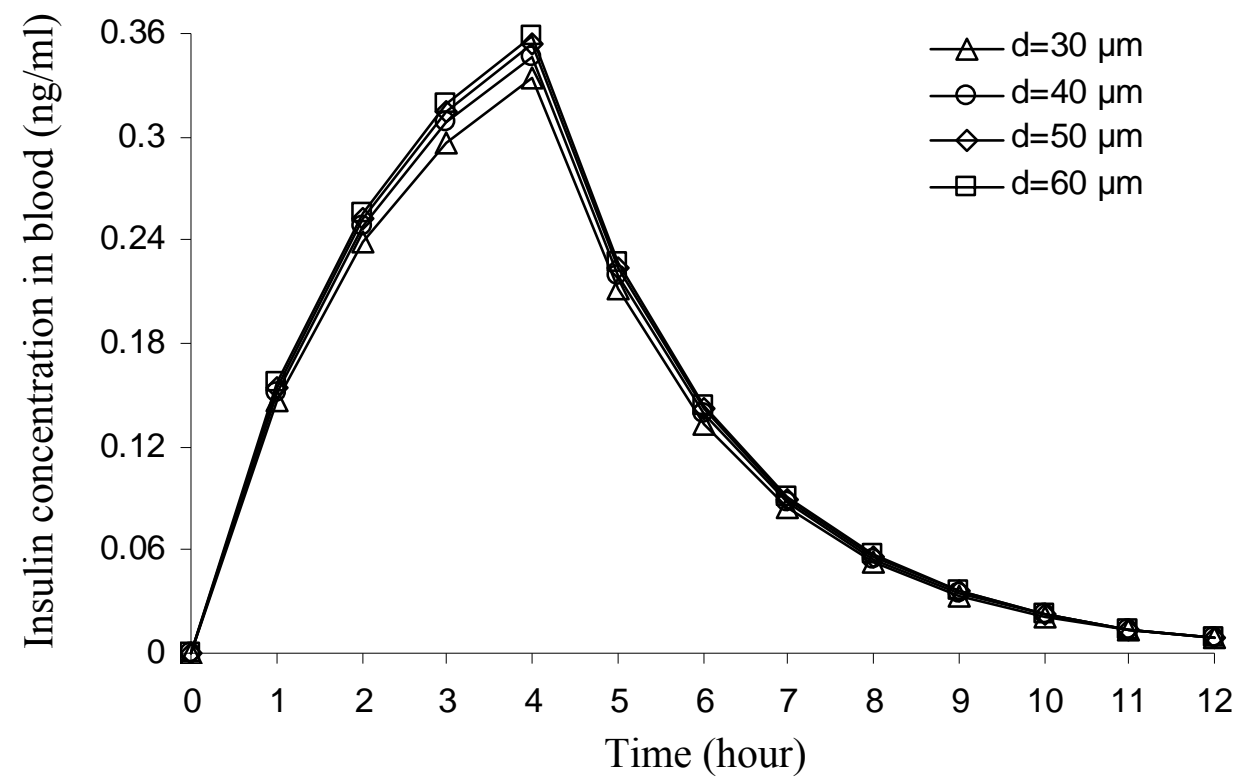

Figure 10. Influence of the diameter (d) of microneedle model (C) on insulin concentration in blood, assuming that the insertion time of microneedles is four hours. 


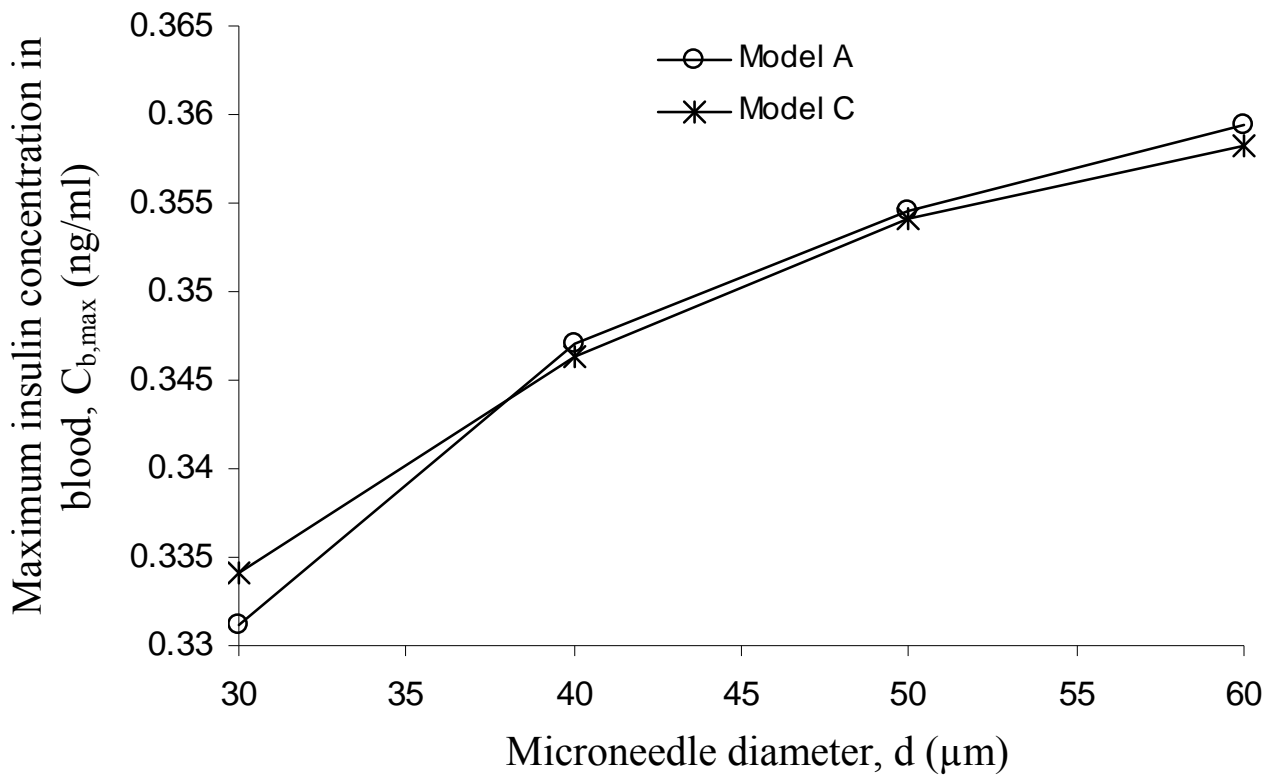

Figure 11. Influence of the diameter (d) of various microneedles models, coated with insulin, on the maximum insulin concentration in blood $\left(\mathrm{C}_{\mathrm{b}, \max }\right)$, assuming that the insertion time of microneedles is four hours. 


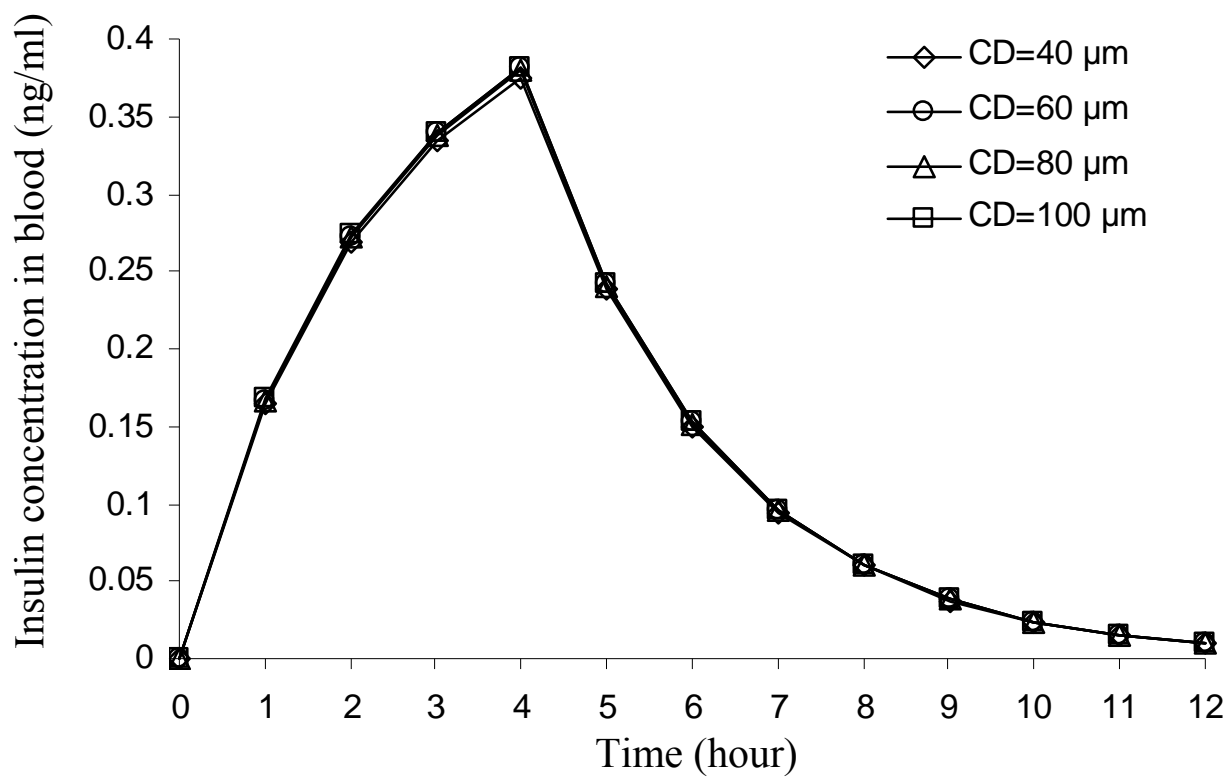

Figure 12. Influence of the coating depth (CD) of microneedle model (D) on insulin concentration in blood, assuming that the insertion time of microneedles is four hours. 


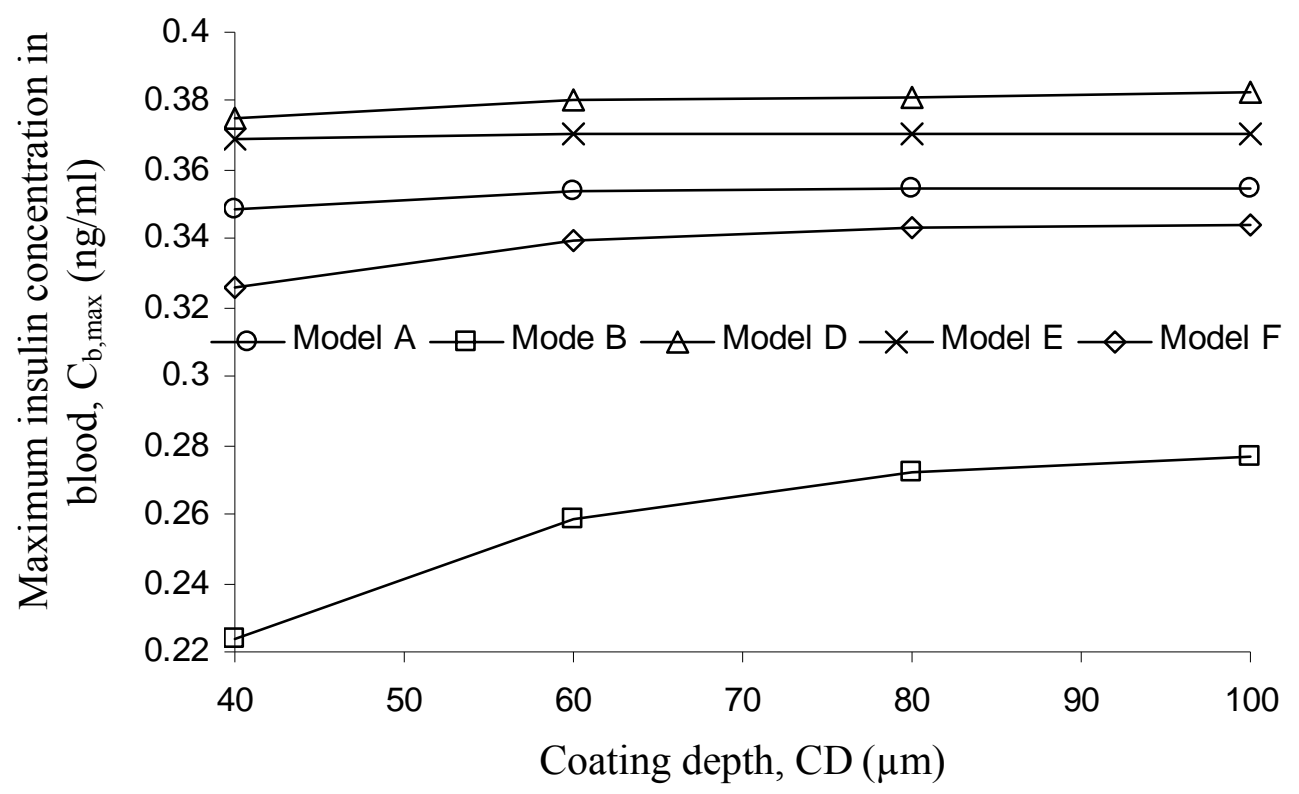

Figure 13. Influence of the coating depth (CD) of various microneedles models, coated with insulin, on the maximum insulin concentration in blood $\left(\mathrm{C}_{\mathrm{b}, \max }\right)$, assuming that the insertion time of microneedles is four hours (the results of microneedle model $\mathrm{C}$ are not included in the figure as they are very similar to the results of microneedle model A). 


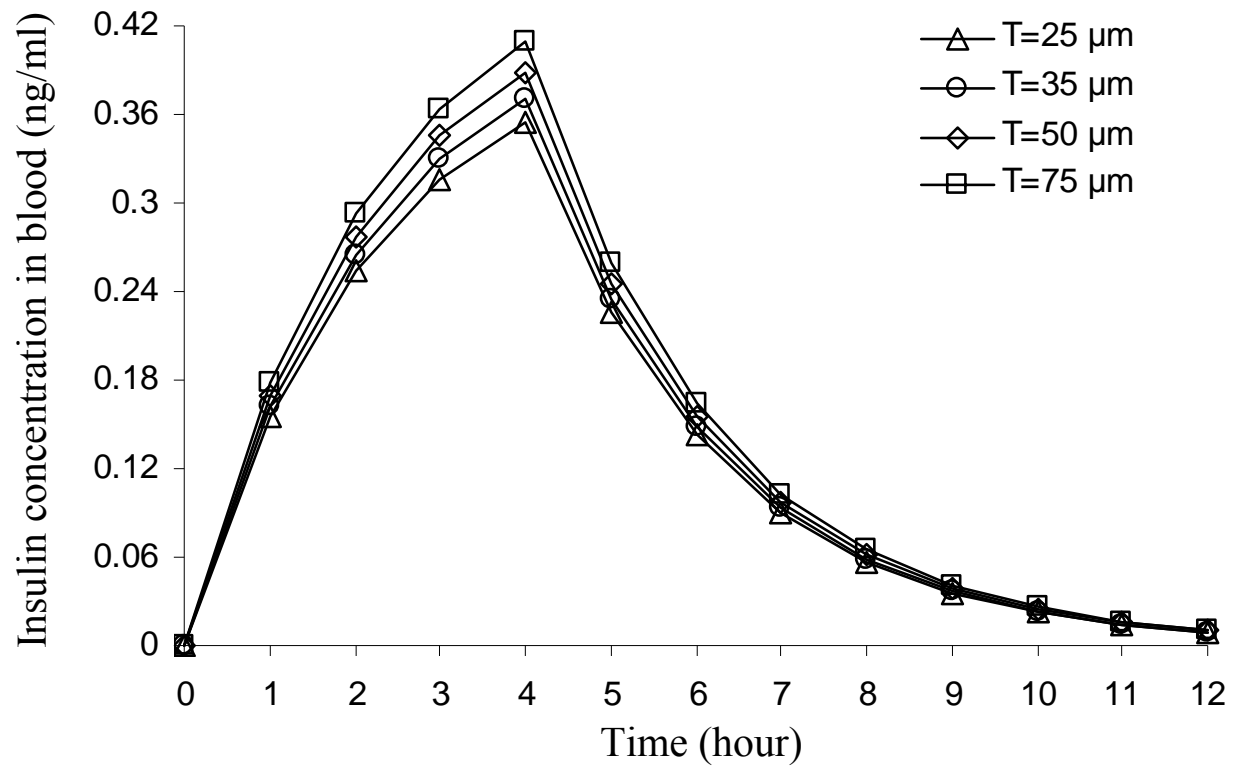

Figure 14. Influence of the thickness $(\mathrm{T})$ of microneedle model $(\mathrm{E})$ on insulin concentration in blood, assuming that the insertion time of microneedles is four hours. 


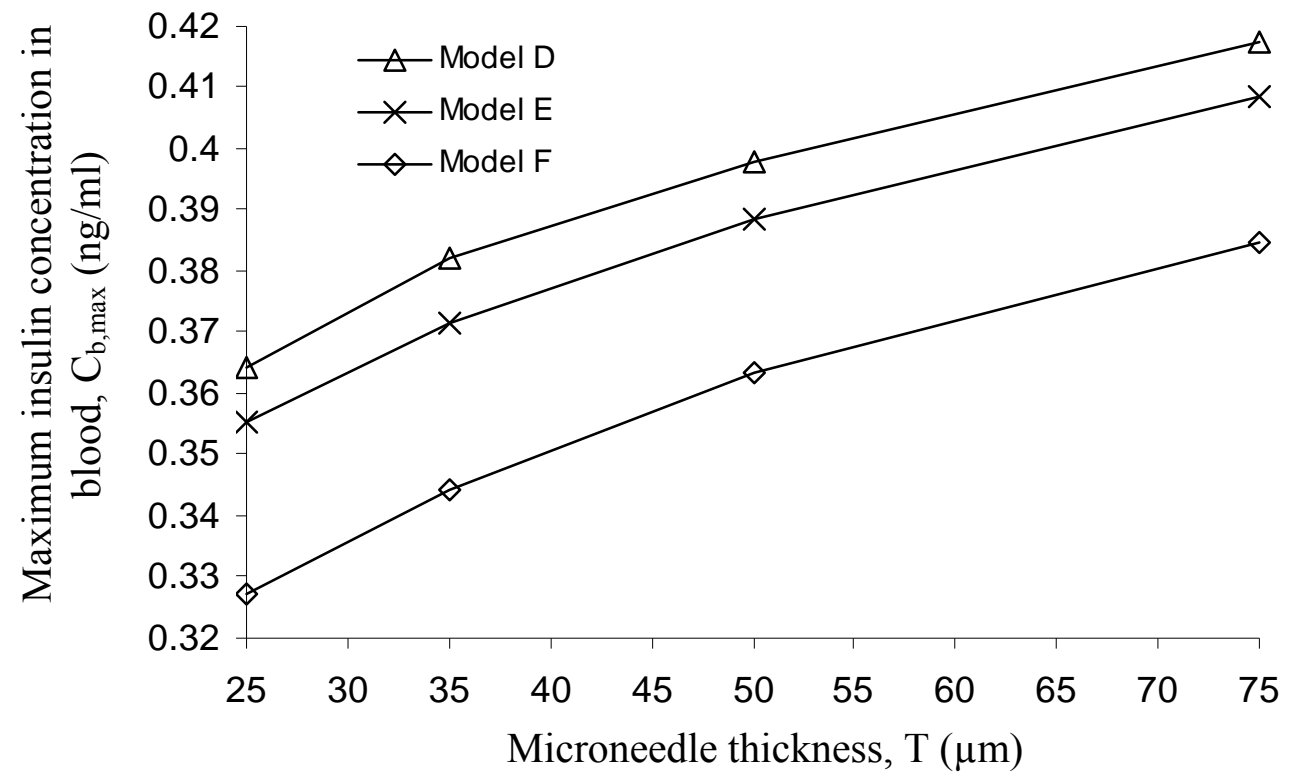

Figure 15. Influence of the microneedle thickness $(\mathrm{T})$ of various microneedles models, coated with insulin, on the maximum insulin concentration in blood $\left(\mathrm{C}_{\mathrm{b}, \max }\right)$, assuming that the insertion time of microneedles is four hours (the dimensions of these microneedle models are as illustrated in Table 1). 


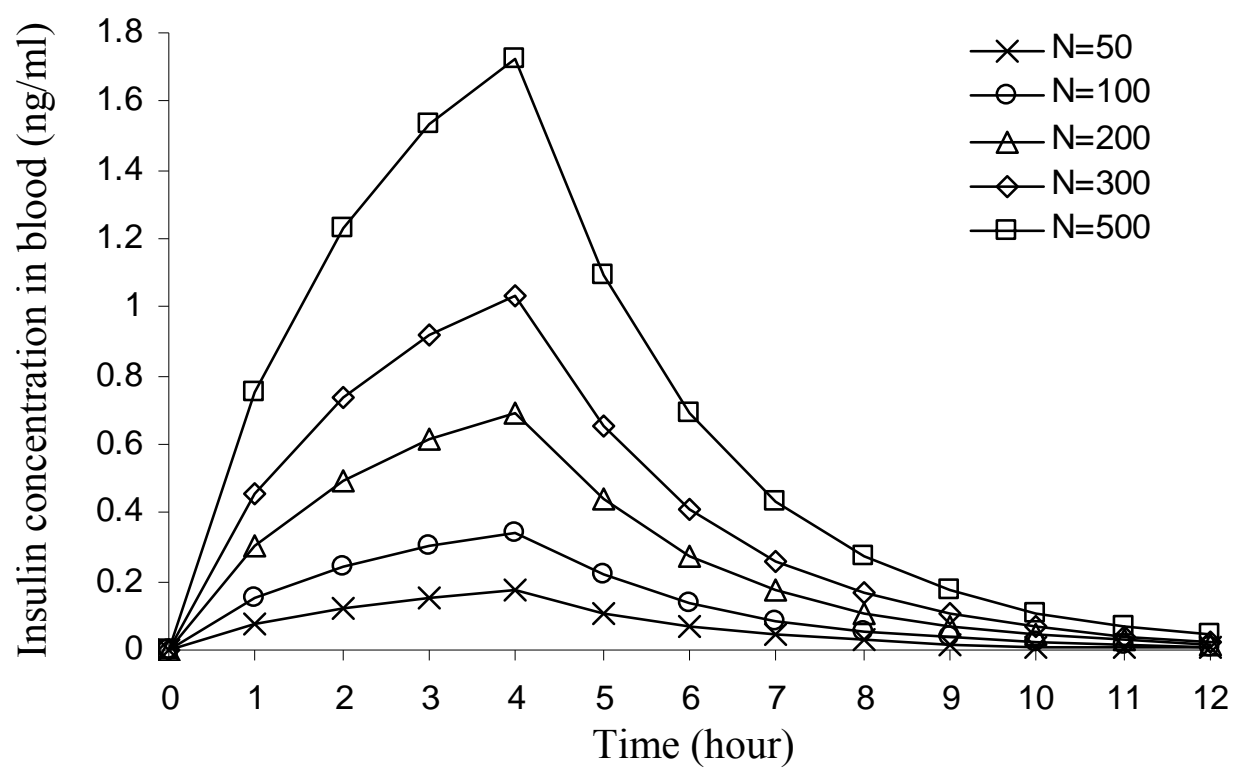

Figure 16. Influence of the number of microneedles in the array $(\mathrm{N})$ of microneedle model $(\mathrm{F})$ on insulin concentration in blood, assuming that the insertion time of microneedles is four hours. 


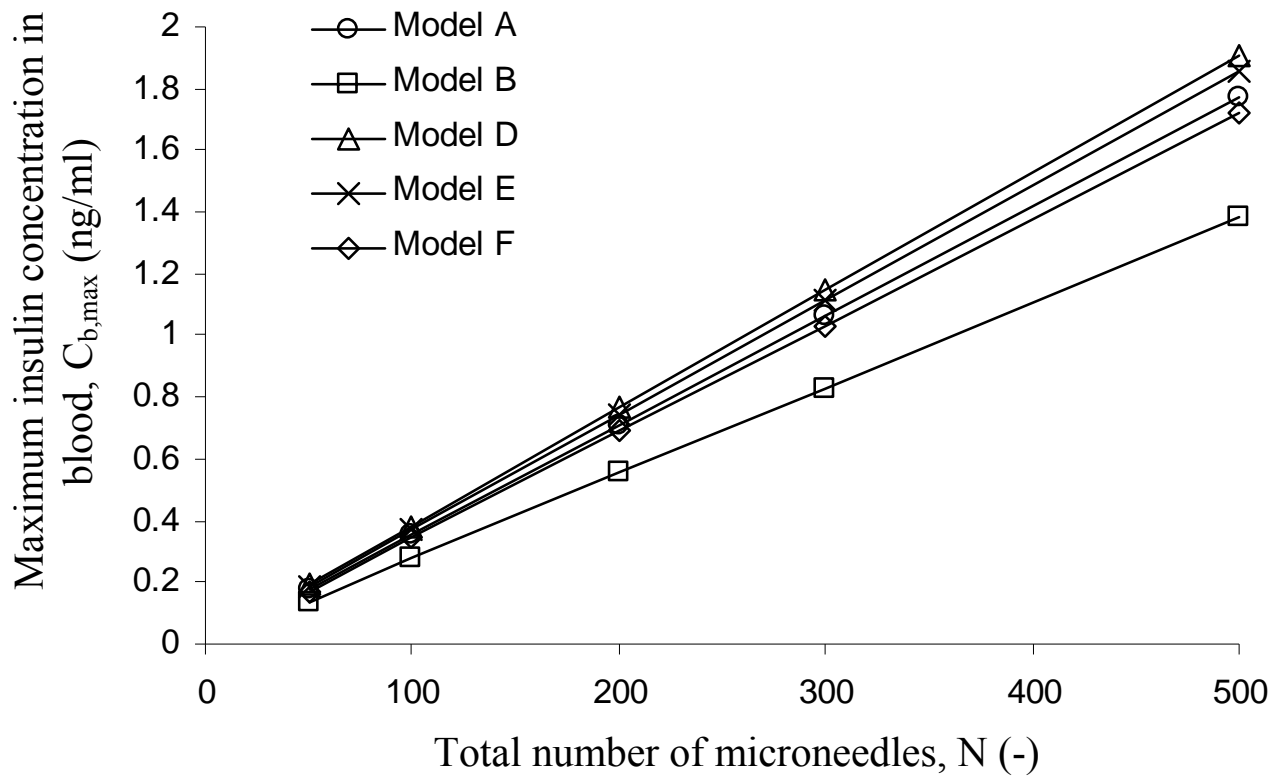

Figure 17. Influence of the total number of microneedles $(\mathrm{N})$ of various microneedles models, coated with insulin, on the maximum insulin concentration in blood $\mathrm{C}_{\mathrm{b}, \max }$, assuming that the insertion time of microneedles is four hours (the results of microneedle model $\mathrm{C}$ are not included in the figure as they are very similar to the results of microneedle model A). 